\title{
ARTÍCULOS
}

\section{HACIA UN MARXISMO CUBANO. EL DEPARTAMENTO DE FILOSOFÍA DE LA UNIVERSIDAD DE LA HABANA EN SUS PRIMERAS ETAPAS (1962-1965)ํ.}

\author{
Valeria González Lage \\ Universidade de Santiago de Compostela \\ valeria.gonzalez@usc.es
}

\begin{abstract}
Resumen: El Departamento de Filosofía de la Universidad de La Habana fue creado fruto de la Reforma Universitaria (enero de 1962) que introducía la obligatoriedad de enseñar filosofía marxista en todas las carreras universitarias y socializar la teoría científica adoptada por la Revolución cubana. Existiría hasta 1971, año en el que cambió de denominación, programas y profesorado. El artículo arroja luz sobre el proceso de creación del Departamento y la evolución de su visión respecto a la enseñanza y teoría del marxismo-leninismo en sus primeras etapas: desde un marxismo ortodoxo y manualista hacia la búsqueda de un punto de referencia cubano, antiimperialista y tercermundista. A través de fuentes orales y de archivo, el trabajo pretende analizar cómo y por qué nació el Departamento, sus objetivos y fuentes teóricas, y el cambio de perspectiva que experimentó su profesorado desde su creación hasta 1965, así como los principales factores que lo incentivaron.
\end{abstract}

Palabras clave: Departamento de Filosofía, Reforma Universitaria, marxismo, Filosofía, manualismo, Revolución cubana, antiimperialismo, tercermundismo.

Tittle: TOWARDS A CUBAN MARXISM. THE PHILOSOPHY DEPARTMENT OF THE UNIVERSITY OF HAVANA IN ITS EARLY STAGES (1962-1965).

\begin{abstract}
The Philosophy Department of the University of Havana was created as a result of the University Reform (January 1962) that incorporated the obligation to teach Marxist philosophy in all university degree programmes and to socialize the scientific theory adopted by the Cuban Revolution. It would exist until 1971, the year in which it changed its name, programmes, and teaching staff. The article casts light on the formative process of the Department and the evolution of its conception regarding the teaching and theory of Marxism-Leninism in its early stages: from an orthodox and manualist Marxism towards the search for a Cuban, anti-imperialist, and Third-Worldist point of reference. Through oral and archival sources, this work aims to analyse how and why the Department was born, its objectives and theoretical sources, and the change in perspective that its teaching staff experienced from its creation to 1965 , as well as the main factors that encouraged it.
\end{abstract}

Keywords: Philosophy Department, University Reform, Marxism, Philosophy, manualism, Cuban Revolution, anti-imperialism, third-worldism.

\footnotetext{
1 Trabajo parte de una tesis doctoral respaldada por el Programa de Ayudas y Movilidad FPU (MICINN, España). Realizado en el Grupo de Investigación HistAmérica, de la USC, GPC, Xunta de Galicia, 2020-2022 y en el marco del proyecto PID2019-105657GB-100 del Ministerio de Ciencia e Innovación.
}

Recibido: 06-06-2021

Aceptado: 20-06-2021

Cómo citar este artículo: GONZÁLEZ LAGE, Valeria. Hacia un marxismo cubano. El Departamento de Filosofía de la Universidad de La Habana en sus primeras etapas (1962-1965). Naveg@mérica. Revista electrónica editada por la Asociación Española de Americanistas [en línea]. 2021, n. 27. Disponible en: <http://revistas.um.es/navegamerica>. [Consulta: Fecha de consulta]. ISSN 1989-211X. 


\section{Introducción}

El Departamento de Filosofía (DF) de la Universidad de La Habana (UH) nació para cumplir con la Reforma Universitaria de 1962, que introducía la filosofía y la economía política marxistas como asignaturas obligatorias en todos los planes de estudio universitarios. Existiría hasta noviembre de 1971, momento en el que fue depurado y reconvertido en Departamento para la Enseñanza del MarxismoLeninismo, con un plantel y unos programas diferentes a los manejados en los años sesenta.

En abril de 1961 la Revolución cubana oficializó su carácter socialista y, meses después, su impronta marxista-leninista. Esta declaración se hizo en una isla en la que el conocimiento de esta ideología era precario y estaba poco extendido, bien entre la población o bien entre los dirigentes. Exceptuando a la militancia del otrora Partido Socialista Popular (PSP) -comunismo tradicional- y a intelectuales y políticos próximos de la teoría marxista por interés propio, pocos eran los que conocían las obras de Marx, Engels o la herencia creada tras ellos. Fueron la tradición de liberación nacional, los ideales de justicia e igualdad social, las profundas transformaciones sociales acometidas por la Revolución y el liderazgo unitario de Fidel Castro los que guiaron a la población cubana a abrazar el socialismo, aun cuando eso supusiese adentrarse en un marco político-ideológico apenas conocido ${ }^{2}$.

La difusión de los objetivos revolucionarios entre la población se emprendió desde los inicios de los sesenta. El socialismo cubano se articuló mediante diversos canales, estructuras y actividades, tanto estatales como de masas. Se trató de un proceso complejo y multidimensional, en el que se sintetizaron las corrientes del nacionalismo decimonónico cubano con aquellas surgidas en el siglo XX y el marxismo adoptado en los sesenta, y en el que estuvieron implicadas distintas esferas: la oficial (doctrina política), la académica (teoría política) y la práctica diaria o esfera popular, con participación de las artes y los medios y las organizaciones de masas $^{3}$.

Uno de los canales privilegiados para la ascendencia del marxismo en los sesenta fue la esfera docente-académica, mediante la cual se persiguió la institucionalización del marxismo como fundamento teórico general dentro del medio

\footnotetext{
${ }^{2}$ Sobre el desconocimiento de la población sobre el marxismo véase KAROL, Kewes S. Los guerrilleros en el poder. Itinerario político de la revolución cubana. Barcelona: Seix Barral, 1972, pp. 60-61 y 67-69.

${ }^{3}$ GORDY, Katherine A. Living ideology in Cuba: Socialism in principle and practice. Ann Arbor. Michigan: University of Michigan Press, 2015, pp. 1-5. Sobre algunos canales utilizados para la socialización de una conciencia revolucionaria en Cuba véase FAGEN, Richard. The Transformation of Political Culture in Cuba. Standford: Standford University Press, 1969. 271 p.; MEDIN, Tzvi. Cuba: The Shaping of Revolutionary Consciousness. London: Lynne Rienner Publishers, Inc., 1990. 191 p.; BUNCK, Julie Marie. Fidel Castro and the quest for a revolutionary culture in Cuba. Pennsylvania: Pennsylvania State University Press, 1994. 237 p. Estos se centran en las organizaciones de masas, la Campaña de Alfabetización, la esfera artística y cultural o las Escuelas de Instrucción Revolucionaria, dedicadas a la formación política de la militancia. Ninguno se centra en la esfera académica ni el DF.
} 
académico, docente y de investigación ${ }^{4}$. En el ámbito universitario, la socialización del marxismo vino con la aprobación de la Reforma Universitaria en enero de 1962, que aspiraba a una instrucción y una educación en función del desarrollo económico-social del país y los objetivos de liberación. La Reforma proyectó una nueva universidad. Reguló las instituciones y órganos de decisión y trastocó la estructura curricular existente, creando un total de cinco facultades en la UH (Humanidades, Ciencias, Tecnología, Ciencias Agropecuarias y Ciencias Médicas), compuestas a su vez por varias escuelas. Dentro de la de Humanidades nacían de modo independiente estudios de historia, ciencias jurídicas, ciencias políticas, educación, economía y letras 5 .

En relación con nuestra investigación, lo más relevante fue que la Reforma impuso la obligación de cursar en todos los planes universitarios filosofía y economía política marxistas. Se optó por no crear aún carreras de filosofía, dada la carencia de profesorado especializado ${ }^{6}$. En su lugar, se decidió constituir Departamentos de Filosofía en las universidades de la isla con la misión de dar servicio a otras escuelas y facultades en esta materia, difundir el marxismo entre docentes y estudiantado, y enseñar materialismo dialéctico e histórico -DIAMAT e HISMAT-. Cuando las circunstancias materiales y humanas lo permitiesen, se configurarían escuelas y carreras de filosofía específicas. Si bien este trabajo se centra en el DF de la Universidad de La Habana, cabe aclarar que se crearían otros homónimos en las Universidades de Las Villas y de Oriente con la misma misión.

EI DF de La Habana nació con un claro afán de socialización del marxismo en la esfera académica y de institucionalización de la filosofía marxista como paradigma para las futuras generaciones de estudiantes y profesores. En su evolución identificamos cuatro etapas de acuerdo con la metodología de la enseñanza y fuentes manejadas, su perspectiva teórica y su organización interna. La primera de ellas se caracterizó por la formación dentro de los cauces de los manuales soviéticos y la podemos situar entre 1962 y 1963, coincidente con la superación de un curso acelerado en la Escuela Nacional Cepero Bonilla y los primeros momentos de enseñanza del profesorado en la Universidad de La Habana. La segunda fase abarcó el bienio 1964-1965, y estuvo marcada por la modificación de los programas docentes y los materiales de estudio en un sentido de negación del manualismo y de búsqueda de nuevas referencias teóricas y heurísticas.

La tercera etapa, entre 1966-1968, fue de maduración teórica, fruto de los debates y los cuestionamientos precedentes. En este período el DF apostó por una perspectiva histórica del marxismo, publicó sus propios materiales y productos intelectuales e incrementó su participación en eventos nacionales y en los circuitos

\footnotetext{
${ }^{4}$ LEÓN DEL RíO, Yohanka. Avatares del marxismo en la década del sesenta en Cuba. En: PLÁ LEÓN, Rafael y GONZÁLEZ ARÓSTEGUI, Mely del R. (coord.). Marxismo y Revolución: escena del debate cubano en los sesenta. La Habana: Editorial de Ciencias Sociales; Centro de Investigación y Desarrollo de la Cultura Cubana Juan Marinello, 2006, p. 59.

${ }^{5}$ Gaceta Oficial de la República de Cuba, La Habana, 10-01-1962, 1a Sección, pp. 374-383.

${ }^{6}$ Revista Cuba Socialista, La Habana, febrero 1962, n. 6, pp. 22-44: RODRÍGUEZ, Carlos R. La Reforma Universitaria. Sobre la Reforma véase MARTíN SABINA, Elvira (ed.). La Reforma Universitaria de 1962: Medio siglo de impacto en la Educación Cubana. La Habana: Félix Varela, 2012. $163 \mathrm{p}$.
} 
internacionales. En la última etapa (1969-1971), el colectivo se vio afectado por críticas hacia su trabajo teórico y docente, por la movilización nacional para lograr la zafra de los 10 millones de azúcar y un complejo contexto nacional que puso en jaque a la puesta por un socialismo independiente. Si bien el colectivo logró mejorar su producción intelectual y organización interna, los cuestionamientos hacia su trabajo y un proceso de cambio en las prioridades de la Revolución condujeron a su dispersión en 1971.

El objeto de este trabajo son las dos primeras fases del Departamento (entre 1962 y 1965). Consideramos que en ellas radican las claves para comprender, por una parte, su evolución global en el segundo lustro de la década y hasta su dispersión en 1971. A partir de 1965-1966 el DF alcanzó un grado de madurez tal que le permitió crear un programa docente y publicar sus propios materiales de enseñanza, además de ganar presencia en la escena intelectual y política de la Revolución. Desde ese momento, el colectivo publicó sus productos intelectuales las revistas Caimán Barbudo (1966-1967) y Pensamiento Crítico (1967-1971)- y pasó a ejercer un rol clave en la configuración de un marco político-ideológico independiente para Cuba y la difusión del modelo socialista cubano a nivel internacional.

Por otra parte, la evolución del DF en estos primeros años fue, en buena medida, reflejo de la evolución de la Revolución en el período: la necesidad de transformación radical y los retos que ello planteaba, la adopción de un paradigma socialista acorde a las raíces nacionales, la búsqueda de una identidad política propia, las carencias materiales y de cuadros y el complejo contexto internacional en el que se desarrollaba la Revolución, signado por el bloqueo norteamericano, la emergencia del tercermundismo como identidad política y las pugnas en el movimiento comunista internacional. El Departamento, al igual que la Revolución, se construyó desde la creatividad, la necesidad, la polémica y la experimentación, a partir de los ideales de liberación y justicia social ${ }^{7}$. La primera mitad de los sesenta, cargada de contradicciones, soluciones transitorias y debates, permitió que, desde 1965, la Revolución madurase un discurso e identidad propios que influyeron en el contexto regional en general, y en los debates de la nueva izquierda de modo específico ${ }^{8}$.

El DF ha recibido escasa atención académica hasta el momento. En la última década se han publicado trabajos enfocados en sus dos principales productos

\footnotetext{
${ }^{7}$ Sobre el contexto véase PÉREZ-STABLE, Marifeli. La Revolución cubana: orígenes, desarrollo y legado. Madrid: Editorial Colibrí, 1998. 371 p.; GUERRA, Sergio y MALDONADO, Alejo. Historia de la Revolución Cubana. Navarra: Txalaparta, 2009. 297 p.; CHOMSKY, Aviva. A history of the Cuban Revolution. Malden: Wiley Blackwell, 2015. 232 p.

${ }^{8}$ ARTARAZ, Kepa. Cuba y la nueva izquierda: una relación que marcó los años 60. Buenos Aires: Capital Intelectual, 2011. 301 p.; MARTíN ÁLVAREZ, Alberto y REY TRISTÁN, Eduardo. La oleada revolucionaria latinoamericana contemporánea, 1959-1996. Definición, caracterización y algunas claves para su análisis. Naveg@mérica. Revista electrónica de la Asociación Española de Americanistas [en línea]. 2012, n. 9. [Consulta: 17-08-2021]. Disponible en: $<$ https://digitum.um.es/digitum/bitstream/10201/36767/1/161591-596161-1-PB.pdf>.
} 
intelectuales, las revistas Caimán Barbudo ${ }^{9}$, Pensamiento Crítico ${ }^{10}$ y la relación de esta última con la nueva izquierda intelectual europea y estadounidense ${ }^{11}$. A estos se añaden investigaciones más amplias sobre la evolución del marxismo cubano en los años sesenta, la política cultural de la Revolución o los vínculos intelectuales entre la isla y la Unión Soviética, en los que se refiere brevemente la historia del $\mathrm{DF}^{12}$

Se han dado a conocer también testimonios y análisis de algunos de sus principales protagonistas, caso de Fernando Martínez Heredia, Aurelio Alonso o Jesús Diaz $^{13}$. Al margen de lo mencionado, no existe hasta ahora una investigación que estudie en profundidad al Departamento y examine su perspectiva de y hacia el marxismo-leninismo, las implicaciones de su creación y de su dispersión, posibles discrepancias teóricas en su interior, fuentes de inspiración o su rol en la configuración político-ideológica de la Revolución y en la socialización de la teoría

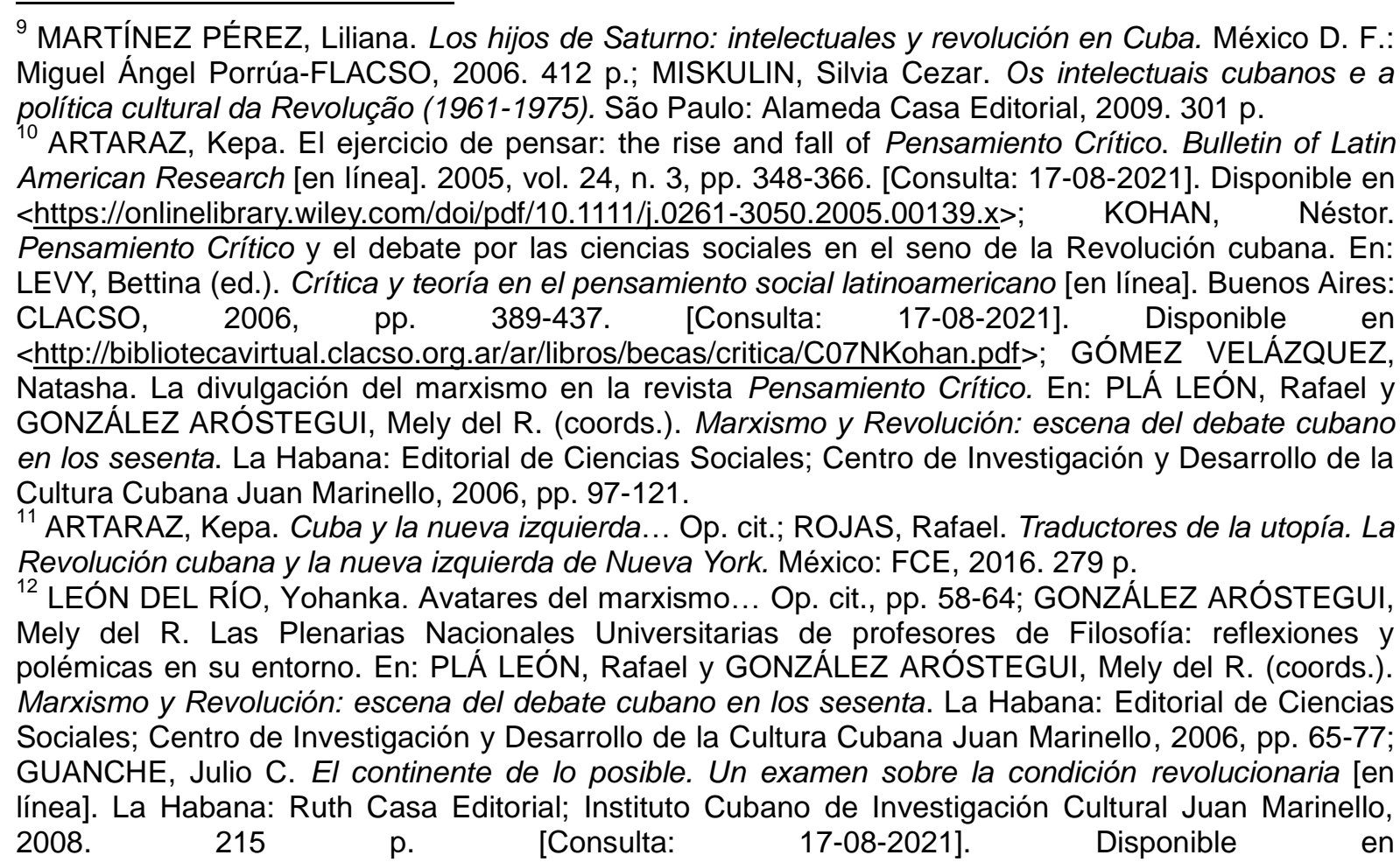
$<$ https://jcguanche.files.wordpress.com/2021/03/el-continente-de-lo-posible.-julio-cesar-guanche.pdf>; PEDEMONTE, Rafael. Una relación tensa y ambivalente: el medio intelectual cubano ante "lo soviético" en los primeros años revolucionarios (1959-1966). Historia [en línea]. 2017, vol. 1, n. 50, pp. 141-173. [Consulta: 17-08-2021]. Disponible en <http://dx.doi.org/10.4067/S0717$71942017000100006>$.

${ }^{13}$ ALONSO, Aurelio. Marxismo y espacio de debate en la Revolución Cubana. Temas. 1995, vol. 1, n. 3, pp. 34-43; MARTÍNEZ HEREDIA, Fernando. A viva voz. La Habana: Editorial de Ciencias Sociales, 2010. 308 p.; MARTÍNEZ HEREDIA, Fernando. El ejercicio de pensar. La Habana: Editorial de Ciencias Sociales, 2010. 158 p; SÁNCHEZ QUIRÓZ, Magdiel (comp.). Fernando Martínez Heredia. Pensar en tiempo de Revolución. Antología esencial [en línea]. Buenos Aires: CLACSO, 2018. 1341 p. [Consulta: 17-08-2021]. Disponible en <http://biblioteca.clacso.edu.ar/clacso/se/20180524041744/Antologia Fernando Martinez Heredia.pd f $>$; DÍAZ, Jesús. El fin de otra ilusión. A propósito de la quiebra de El Caimán Barbudo y la clausura de Pensamiento Crítico. Encuentro de la cultura cubana. 2000, n. 16-17, pp. 106-119. Véanse también los testimonios recogidos en Biblioteca Nacional José Martí. Multimedia Pensamiento Crítico. Una revista para el ejercicio de pensar [CD-ROM]. La Habana: Biblioteca Nacional José Martí, 2016. S. pág. 
marxista.

Esta investigación se nutre principalmente de documentación privada, fuentes orales y hemerográficas. En primer lugar, está sustentada en documentos conservados por una integrante del DF desde su creación. Este alberga escritos producidos por el colectivo con datos sobre los programas docentes, la bibliografía y su organización interna. Esta documentación privada no está catalogada ni sistematizada y parte carece de data y título, lo que plantea algunas particularidades para su referenciación ${ }^{14}$. En segundo lugar, este estudio bebe de entrevistas concedidas por miembros del DF durante dos estancias desarrolladas en La Habana ${ }^{15}$. Por último, también se ha recurrido a la revista Cuba Socialista: en concreto, a artículos publicados en los años sesenta sobre las Escuelas de Instrucción Revolucionaria (EIR) y la difusión de la filosofía marxista en la isla ${ }^{16}$.

El trabajo se estructura en cuatro apartados. El primero examina el proceso de creación del Departamento desde la aprobación de la Reforma Universitaria hasta su constitución oficial en 1963. El segundo analiza la que, a grandes rasgos, hemos identificado como primera etapa del DF (1962-1963), poniendo el foco de atención en su organización interna y los programas docentes y materiales de estudio manejados. El tercero indaga en los años 1964-1965, claves para comprender el cambio de perspectiva del colectivo, su rechazo al manualismo y la introducción de una mirada de corte histórica en la enseñanza del marxismo. En las conclusiones se ofrece un balance crítico de la evolución experimentada por el DF en la primera mitad de los sesenta, poniéndola en relación con la deriva que este siguió en años posteriores.

\section{La creación del Departamento de Filosofía de la Universidad de La Habana}

Una vez promulgada la Reforma Universitaria en enero de 1962, se reclutó a un grupo pequeño de docentes para emprender la tarea de enseñar marxismoleninismo en la UH. Este sería el germen del futuro DF. El grupo estaba compuesto al menos por los extranjeros Bolney Ortega Montenegro y Gustavo Davidson, y los cubanos Jesús Díaz, Isabel Monal y Juan Guevara Valdés. Este último permaneció

\footnotetext{
${ }^{14}$ Documentación Privada de la Profa. Niurka Pérez (en adelante, DPNP), consultada en La Habana. Nuestro agradecimiento por su generosidad. Se entrecomillarán los títulos reflejados en los documentos. Si no están titulados, se pondrá uno descriptivo sin comillas. Solo se recogerá el autor que conste en la documentación. En cuanto a la fecha, se indicará la reflejada en la fuente; si esta no aparece, se pondrá una aproximada siempre que sea posible, precedida por "ca." (circa) o "post".

${ }^{15}$ Entrevistas de la autora con Aurelio Alonso Tejada (13-11-2017, 11-10-2018, 06-12-2018); Thalía Fung Riverón (04-12-2018); Marta Pérez-Rolo (07-11-2017); Elena Díaz González (15-11-2017); Rolando Rodríguez García (21-10-2018); Niurka Pérez Rojas (23-10-2017); Marta Blaquier Ascaño (30-10-2017) e Isabel Monal Rodríguez (27-11-2018), realizadas en La Habana. La información aportada por ellas y ellos hará referencia a estas entrevistas. Sólo se citarán de nuevo las de Aurelio Alonso, para aclarar la data. A estas se les añade un testimonio escrito por A. Alonso, facilitado a la autora en el otoño de 2018: ALONSO, Aurelio. Perder y ganar en el juego de la vida. Fragmentos de un borrador de libro en proceso de redacción.

${ }^{16}$ Cuba Socialista existió entre 1961 y 1967, período considerado como su "Primera Época", a la que le seguirían una "Segunda" y "Tercera Época" posteriormente. Constituyó un medio de expresión de la dirección política cubana. El Consejo de Redacción durante su "Primera Época" estaba compuesto por Fidel Castro, Osvaldo Dorticós Torrado, Blas Roca, Fabio Grobart y Carlos Rafael Rodríguez. Se citará al pie de página como fuente primaria, indicando fecha, número, autoría y título de artículo.
} 
en el colectivo hasta 1966, mientras que Monal lo hizo hasta 1967 aproximadamente. El más joven era Jesús Díaz, quien, con solo veintiún años y formación diplomática, fue designado por la Unión de Jóvenes Comunistas (UJC) ${ }^{17}$ para incorporarse al incipiente centro. Gustavo Davidson y Bolney Ortega, abandonarán posteriormente el colectivo: en 1963 el primero, poco después el segundo.

Para ampliar este protogrupo inicial y dotar al DF de suficiente profesorado, se organizó un curso de formación acelerada. Se llevó a cabo dentro del sistema de Escuelas de Instrucción Revolucionaria (EIR), conocidas como "Escuelas del Partido". Estas se habían creado en diciembre de 1960 para instruir política e ideológicamente a los cuadros y la militancia partidaria. Impartieron, sobre todo en sus inicios, cursos de adoctrinamiento ${ }^{18}$.

Constaban de tres niveles de enseñanza. El escalón más elemental lo constituían las Escuelas Básicas de Instrucción Revolucionaria (EBIR), en las que se estudiaban principalmente discursos de los dirigentes cubanos y el libro Los fundamentos del socialismo en Cuba escrito por Blas Roca, secretario general del PSP desde los años 30. El segundo nivel, las Escuelas Provinciales de Instrucción Revolucionaria (EPIR), contaba con más ambición y diversidad, con clases sobre filosofía y economía política marxistas, historia del movimiento obrero e historia de Cuba. Por último, las Escuelas Nacionales de Instrucción Revolucionaria (ENIR), el nivel superior, incorporaban mayor complejidad teórica con el estudio profundo del materialismo dialéctico e histórico y la economía política a través de manuales soviéticos, clásicos del marxismo y textos producidos por la dirección de la Revolución cubana ${ }^{19}$.

Bajo este esquema de las EIR, en 1962 se creó una Escuela Nacional dirigida exclusivamente a formar a profesores de economía política y filosofía marxistas para que, luego, impartiesen estas materias en las universidades cubanas, tal y como se había estipulado en la Reforma Universitaria. Esta se llamó Escuela Nacional Cepero Bonilla, funcionó únicamente hasta 1963 y estuvo a cargo de Felipe Sánchez Linares (EIR) como director, y Pedro Rodríguez y José Cantón Navarro como subdirectores ${ }^{20}$.

Estaba dividida en dos cursos simultáneos: uno de economía política y otro de filosofía marxista, cada uno con sus respectivos contenidos y programas. La

\footnotetext{
${ }^{17}$ La UJC se creó oficialmente en abril de 1962 como organización partidista unitaria de la juventud, dependiente del Partido Unido de la Revolución Socialista de Cuba (PURSC) y, desde 1965, del Partido Comunista de Cuba (PCC). Su antecedente fue la AJR o Asociación de Jóvenes Rebeldes (1959-1962).

${ }_{18}$ DÍAZ SOSA, Fidel. El proceso de difusión del marxismo soviético en Cuba. Apuntes preliminares. En: PLÁ LEÓN, Rafael y GONZÁLEZ ARÓSTEGUI, Mely del R. (coords.). Marxismo y Revolución: escena del debate cubano en los sesenta. La Habana: Editorial de Ciencias Sociales; Centro de Investigación y Desarrollo de la Cultura Cubana Juan Marinello, 2006, p. 82.

${ }^{19}$ Sobre las EIR véase: FAGEN, Richard. The Transformation of Political Culture... Op. cit., pp. 104137; y DÍAZ SOSA, Fidel. El proceso de difusión... Op. cit., pp. 78-96.

${ }^{20}$ El nombre fue acordado por los alumnos como homenaje a Raúl Cepero Bonilla, fallecido en un accidente aéreo en noviembre de 1962 tras haber sido ministro de Comercio y presidente del Banco Nacional de Cuba.
} 
docencia en ambos casos corrió a cargo de profesores hispanosoviéticos, "niños de la guerra" exiliados en la Unión Soviética durante el conflicto civil español, condición que facilitaba su inserción idiomática en la isla. El grupo de economía política estuvo dirigido por Anastasio Mansilla, economista y especialista en El Capital. El de filosofía por Luisa Arana Larrea, psicólogo de formación.

Será en el grupo de filosofía marxista de la Escuela Nacional Cepero Bonilla en el que nos detendremos, puesto que ahí se formaron la mayoría de los miembros del DF. A partir de las entrevistas realizadas se deduce que el proceso de selección del alumnado estuvo coordinado principalmente por dirigentes de la Unión de Jóvenes Comunistas (UJC) y la Federación Estudiantil Universitaria (FEU). Los candidatos provenían casi enteramente del estudiantado universitario, de años superiores en buena medida y especialmente del área de Humanidades. Ser militante de la UJC u otras organizaciones de masas no fue un requisito definitorio. Sin embargo, sí se demandaban signos de compromiso con las metas de la Revolución.

Al menos la mitad de los entrevistados habían sido integrantes de la Asociación de Jóvenes Rebeldes (AJR) ${ }^{21}$, de las Organizaciones Revolucionarias Integradas $(\mathrm{ORI})^{22}$ o de las Milicias Nacionales Revolucionarias (MNR) ${ }^{23}$. Niurka Pérez, Fernando Martínez Heredia y Marta Blaquier habían participado además en el llamado "Plan Fidel". Esta iniciativa, lanzada por el Gobierno en 1961, consistió en la formación de un plantel de profesorado de secundaria básica que se encargase de instruir a la población recién iniciada en la Campaña de Alfabetización. Por tanto, la selección se hizo a partir de una triple conjunción de criterios: un criterio docente (experiencia), un criterio académico (expediente) y, en especial, un criterio políticoideológico, en el sentido de afinidad y compromiso con la Revolución cubana.

Del total de candidatos internos en la Escuela Nacional Cepero Bonilla (104), 21 fueron designados para integrar el DF. En febrero de 1963 quedaba así ampliado y oficialmente creado para la docencia el Departamento de Filosofía de la Universidad de La Habana. Comenzó a trabajar con un total de 25 miembros: por un lado, la veintena de profesores recién adiestrados en la ENIR; por otro, Isabel Monal, Jesús Díaz, Bolney Ortega y Juan Guevara como parte de aquel protogrupo inicial reclutado anteriormente ${ }^{24}$. Se situó físicamente al lado de la colina universitaria y continuó durante 1963 bajo la dirección de Luis Arana. Este Departamento era un órgano de servicios, no contaba con alumnado propio, sino que estaba constituido por profesorado que impartía filosofía marxista en los currículos de la UH.

\footnotetext{
${ }^{21}$ Véase nota $\mathrm{n}^{0} 17$.

${ }^{22}$ Las ORI fueron la primera organización política unida de la Revolución, entre 1961 y 1962 . Fueron sucedidas por el PURSC (Partido Unido de la Revolución Socialista de Cuba) y, desde 1965, por el PCC (Partido Comunista de Cuba).

${ }^{23}$ Las MNR nacieron en octubre de 1959 como una organización cívico-militar para defender la isla ante una posible agresión militar de los Estados Unidos. Sobre las organizaciones de masas véase KAPCIA, Antoni. Cuba in revolution. A history since the fifties. London: Reaktion Books, 2008, pp. 6488.

${ }^{24}$ Datos recogidos en DPNP: Historia y evolución del Departamento de Filosofía y Pensamiento Crítico, s. tít., s. f. (post 1971), 7 pp. Sobre el proceso de constitución del DF y su evolución véase MARTÍNEZ PÉREZ, Liliana. Los hijos de Saturno... Op. cit.; KOHAN, Néstor. Pensamiento Crítico y el debate por las ciencias sociales... Op. cit.
} 
La Escuela Nacional Cepero Bonilla organizó otro curso a fines de 1963 que añadió 5 miembros más al DF. Desde entonces dejó de funcionar, el DF se desligó de las EIR y pasó a estar inscrito en la Universidad, dependiente del Rectorado y con un sistema propio de docencia y superación. En adelante las EIR y el DF discurrirán vidas separadas e incluso enfrentadas. Su metodología de la enseñanza, textos de estudio y posicionamiento teórico se irán diferenciando a lo largo de la década.

Entre 1962 y 1971 pertenecieron al DF un total de 102 miembros de origen cubano y cerca de una docena de procedencia extranjera ${ }^{25}$. Su dirección cambió en varias ocasiones: Luis Arana (1962-1963), Gaspar Jorge García Galló (1964-1966), Rolando Rodríguez García (1965-1966) ${ }^{26}$, Fernando Martínez Heredia (1966-1969) y Marta Pérez-Rolo (1969-1971).

\section{Una formación “de manual” (1962-1963)}

La primera etapa del DF se corresponde con la formación acelerada que recibió la mayoría del colectivo durante 1962 y el primer año de docencia una vez que comenzaron a prestar sus servicios en la UH en febrero de 1963, fecha oficial de la fundación del DF. Luis Arana continuó como director durante ese año. Además, se creó un Consejo de Dirección integrado por Jesús Díaz, Aurelio Alonso, Juan Guevara, Fernando Martínez Heredia, Isabel Monal y Luisa Noa para asistir a Arana en la estructuración del colectivo y la organización docente ${ }^{27}$.

Los materiales de estudio utilizados tanto en la Escuela Nacional Cepero Bonilla como en el primer año de docencia eran en su mayoría manuales de la Academia de Ciencias de la URSS, publicados durante los años cincuenta. En esta etapa, el DF interiorizó y difundió en las aulas concepciones prácticas y teóricas contra las que parte de este acabaría luchando más adelante.

En la Escuela Nacional Cepero Bonilla, Luis Arana impartía clases diarias sobre materialismo dialéctico e histórico combinadas periódicamente con otras sobre historia de la Revolución de Octubre (a cargo de $\mathrm{M}^{\mathrm{a}}$ Cristina Miranda, también hispanosoviética), historia de Cuba, historia de la filosofía y colonialismo y subdesarrollo, ofrecidas por los cubanos Sergio Aguirre, Isabel Monal y Pelegrín Torras respectivamente. Si bien filosofía y economía eran cursos independientes dentro de la Escuela, los candidatos a profesores de marxismo también recibieron seminarios sobre El Capital.

El texto básico era el manual soviético Los fundamentos de Filosofía Marxista, escrito por F. Vasilievich Konstantinov en 1958. Este se convirtió en el texto soviético de filosofía marxista por antonomasia y se tradujo a más de cinco idiomas diferentes al ruso. En la Escuela Nacional Cepero Bonilla estudiaban la sucesión de epígrafes

\footnotetext{
${ }^{25}$ Datos recogidos en DPNP: "Los compañeros que pertenecieron al Departamento de Filosofía y Pensamiento Crítico, después de 1971", s.f. (post 1971), 2 pp.

${ }^{26}$ Como veremos, Rodríguez era oficiosamente director, si bien García Galló continuaba oficialmente en ese cargo.

${ }^{27}$ DPNP: Historia y evolución del Departamento de Filosofía y Pensamiento Crítico, s. tít., s.f. (post 1971), $7 \mathrm{pp}$.
} 
del manual. Este estaba dividido en dos partes diferenciadas, una consagrada al materialismo dialéctico y otra al materialismo histórico, precedidas por una introducción en la que se presentaba el objeto y problema fundamental de la filosofía ${ }^{28}$.

Se utilizó bibliografía complementaria (y secundaria) al libro de Konstantinov, que incluía otros textos de procedencia soviética. Un ejemplo fue el Manual de Marxismo-Leninismo de O. Kuusinen o Historia de la Filosofía escrito por M. A. Dynnik y otros autores ${ }^{29}$. El primero recogía una exposición popular sobre los principios básicos del marxismo-leninismo, con secciones sobre la filosofía, la economía política y el socialismo científico. El "Dynnik", como fue denominado, constaba de tres tomos y, según el recuerdo de Isabel Monal, retrataba la historia de la filosofía de forma maniquea, a partir de una división entre idealistas y materialistas. Figuras adscritas convencionalmente al idealismo como corriente filosófica recibían poco más que un examen esquemático que acababa por escamotear cualquier análisis y valoración en profundidad de sus aportes filosóficos.

Durante el curso también se aproximaron a clásicos del marxismo. Trabajaron sobre Materialismo y Empiriocriticismo o El Estado y la Revolución de V. I. Lenin, el Anti-Dühring y El origen de la familia, la propiedad privada y el Estado de F. Engels; El 18 de Brumario de Luis Bonaparte y La Guerra civil en Francia de K. Marx; y La Sagrada Familia y El Manifiesto del Partido Comunista escrito por los dos fundadores del marxismo. Estas fueron las principales lecturas iniciáticas, a las que se les añadían otras fragmentarias según las indicaciones del profesor. El corpus clásico con más peso en la Escuela Nacional Cepero Bonilla fue el de carácter filosófico. Para Aurelio Alonso, se primaba al Marx filosófico, "el menos Marx que había", puesto que fue la negación absoluta de la sistematización del pensamiento marxista $^{30}$.

Una vez creado oficialmente el DF e iniciada su andadura docente en febrero de 1963, el pensum del colectivo continuó dentro de los marcos teóricos comentados. El programa de filosofía marxista se impartía a lo largo de dos semestres, dividido en dos asignaturas Ilamadas Materialismo Dialéctico e Histórico I y II. Este seguía la estructura sistémica recogida en el manual de Konstantinov, si bien con adaptaciones necesarias por las limitaciones que la duración del curso imponía.

Hemos consultado la guía docente utilizada por las Escuelas Nacionales de las EIR. En esta se constata que su programa era muy similar al manejado por el DF en estos momentos iniciales, independientemente de que en cada institución se diesen diferentes grados de profundización en función del tiempo de los cursos. En el nivel superior de las EIR se reservaba un último tema para analizar la Revolución cubana y su aporte a la concepción materialista de la historia. Este recurso a la mirada

\footnotetext{
${ }^{28}$ DPNP: "Curso de Filosofía Marxista-Leninista", 1962, 56 p., manuscrito (ms.). Los contenidos del manual están disponibles en línea: <https://www.filosofia.org/urss/kons.htm>. [Consulta: 17-08-2021].

${ }^{29}$ DPNP: "Historia de la Filosofía. Curso superior de Filosofía Marxista y Economía Política", 1962, 22 p., ms. Néstor Kohan trata los contenidos de los manuales soviéticos en el libro: Marx en su (Tercer) Mundo. Hacia un socialismo no colonizado. La Habana: Centro de Investigación y Desarrollo de la Cultura Cubana Juan Marinello, 2003, pp. 50-53.

${ }^{30}$ Entrevista con Aurelio Alonso, 13-11-2017.
} 
nacional era marginal en relación con el conjunto del programa, pretendía encajar el estudio de la experiencia cubana dentro del marco conceptual del DIAMAT e HISMAT y analizarla a la luz de las leyes estudiadas a lo largo del programa docente $^{31}$. Desconocemos si este mismo epígrafe estaba incorporado en el currículum del DF, aunque dada la similitud entre los programas, es plausible. De hecho, sí conocemos que en la guía docente del Departamento se incorporaban ejemplos extraídos de la realidad nacional. Esta guía sufriría adaptaciones ya en su primer año de implantación para incorporar en la medida de lo posible referencias a la práctica social cubana e incluir adaptaciones a las carreras en las que se impartían clases $^{32}$.

En el DF se impuso una organización interna que se mantuvo hasta su depuración -con algunas variaciones-. El esqueleto básico del colectivo fue la organización docente. Sus integrantes estaban distribuidos en tres grupos de acuerdo con las grandes áreas universitarias en las que impartían sus clases. Es decir, la estructura estaba en función de las disciplinas con las que cada profesor se relacionaba en su ejercicio docente cotidiano. Cada grupo contaba con un responsable y un seminario docente semanal obligatorio en el que se ofrecía un balance de experiencias, avances y errores y se formaban pedagógicamente, con discusiones sistemáticas de los contenidos del programa y posibles modificaciones. Esta distribución docente se mantuvo hasta el final del colectivo. En estos momentos iniciales, la meta consistía en dominar los temas del programa. En años posteriores, los seminarios tendrán otra significación, por cuanto servirán como germen de una renovación pedagógica y como foro a partir del cual modificar los contenidos de la asignatura.

A la par de la organización docente, el DF desarrolló lo que se llamó plan de superación. Se trataba básicamente de un proyecto de estudio interno para elevar la formación del profesorado y paliar las deficiencias con las que había comenzado a impartir aulas. Pese a haber recibido el curso acelerado en filosofía marxista, aún no manejaban plenamente el programa docente ni los clásicos marxistas. La mayoría de los miembros tenía entre veinte y veinticinco años en 1963 y una parte de ellos no había finalizado siquiera sus estudios universitarios. La mejora en experiencia pedagógica y conocimiento del marxismo-leninismo se sintió también como paliativo ante los diferentes grados de aceptación que la filosofía marxista y los docentes confrontaban por parte de las facultades. En algunas eran un personal no siempre bien recibido, responsable de contenidos poco deseados o exclusivos de figuras con más experiencia o trayectoria marxista ${ }^{33}$.

\footnotetext{
${ }^{31}$ Archivo Histórico del Instituto de Historia de Cuba, La Habana, Fondo CC-PCC 10.1, Carpeta 16, Expediente 52, Documento 415, Folios 37-40: "Programa de clases de Filosofía y Materialismo Dialéctico. Información abreviada sobre el funcionamiento de las Escuelas", s. f. (ca. 1962). Documento en el que se recoge el programa y bibliografía para el nivel nacional de las Escuelas.

${ }^{32}$ Datos extraídos de DPNP: Actas de la reunión del DF con Osvaldo Dorticós y otras autoridades, s. tít., 20-02-1964, 43 pp.

${ }^{33}$ DPNP: Historia y evolución del Departamento de Filosofía y Pensamiento Crítico, s. tít., s.f. (post 1971), 7 pp. Monal y Alonso también declararon que algunos miembros del DF no fueron recibidos con agrado en algunas facultades: entrevista con Monal y ALONSO, Aurelio. Perder y ganar en el juego de la vida. Fragmentos de un borrador de libro en proceso de redacción.
} 
Este sistema de formación constaba de cursos y seminarios, habitualmente semanales, clasificados en generales y especializados. Los primeros, por su relevancia para la profundización en la teoría marxista, eran de carácter obligatorio para todo el colectivo. Los segundos hacían referencia a temáticas concretas y se desarrollaban en grupos específicos en función de las necesidades departamentales, las inclinaciones personales y, sobre todo, buscando una afinidad con las carreras donde se ofrecían clases. Todos los integrantes debían pertenecer a un equipo de superación particular, además de seguir la formación general. A mayores, existía la superación individual: estudio de idiomas, lecturas de apoyo y rematar las carreras universitarias iniciadas y paralizadas por el traslado al Departamento.

Dentro de esta formación, se estableció por ejemplo un seminario sobre El Capital. Aunque habían recibido conferencias sobre esta obra en la Escuela Nacional Cepero Bonilla, estas habían sido semanales -no diarias-, insuficientes para lograr una comprensión profunda y crítica del principal texto de economía política marxista. Volvieron también sobre Materialismo y Empiriocriticismo y sobre el examen de las leyes y categorías de la dialéctica materialista. En general, se impuso como obligación leer a los clásicos del marxismo, a cuyos contenidos se habían aproximado sólo parcialmente y a través de los manuales en buena medida.

Una de las actividades de superación grupal más reseñables fue el seminario sobre historia de la filosofía que impartió Justo Nicola Romero durante más de un año. Este había sido uno de los pocos filósofos que permaneció en Cuba después del triunfo de la Revolución. Tras haber fungido como rector de la Universidad de Oriente en 1960, se trasladó a La Habana y pasó a colaborar con el DF. Nicola ofreció un seminario general sobre historia de la filosofía y otro especializado sobre lógica.

Los cursos de Nicola son relevantes porque ilustran el afán del colectivo por ensanchar sus campos de conocimiento y por la huella que dejaron en su evolución teórica y pedagógica. En nuestras entrevistas se describe la visión de este filósofo como poco convencional y al margen del esquematismo plasmado en los manuales. Nicola defendería que, para lograr un entendimiento crítico de su materia, era necesario establecer un diálogo directo con los escritos y filósofos de cada época. Sólo así se evitaba el excesivo apego a las historizaciones e interpretaciones y la tendencia a acercarse a la historia de la filosofía con prejuicios, a través de una categorización previa entre materialismo e idealismo. Según A. Alonso, la perspectiva de Nicola influyó positivamente en la herejía que iría desarrollando parte del colectivo, por cuanto ayudó a romper esquemas preconcebidos y animó un contacto estrecho con los escritos producidos en cada época ${ }^{34}$.

El período de constitución del DF se definió en buena medida a partir del ejemplo brindado por la URSS. Este apego al prototipo y a los recursos soviéticos se explica por varios motivos. Por una parte, por el influjo que habrían ejercido los hispanosoviéticos Anastasio Mansilla y Luis Arana en la formación incipiente del alumnado en la Escuela Nacional Cepero Bonilla. Esta influencia es interpretada de

\footnotetext{
${ }^{34}$ Entrevista con Aurelio Alonso, 11-10-2018.
} 
diferente modo en los testimonios recogidos. Por un lado, se incide en la distinta formación de estos dos profesores: mientras que Mansilla era especialista en economía política y concretamente en El Capital, Luis Arana no era filósofo ni se había especializado en teoría marxista. Para Isabel Monal, esta peculiaridad en la formación de Arana podría haber sido un error de partida y haber contribuido al uso del manual desde el comienzo.

Por otra parte, la influencia de los profesores hispanosoviéticos es vista a partir del grado de ortodoxia que transmitían en sus respectivas clases. En nuestros testimonios se caracteriza a Arana como una persona con una dimensión mental y una proyección conceptual amplia, a diferencia de Mansilla. Aunque el primero era prosoviético, su pensamiento no se asociaría a un férreo dogmatismo, ventaja que habría incentivado un marco para el debate ${ }^{35}$.

Además del profesorado, el factor que tuvo más peso para tomar como referente el ejemplo y los materiales soviéticos fue el contexto en el que se introdujo el marxismo. El fenómeno de socialización de la teoría marxista en Cuba también tiene historia y, como tal, está atravesado por condicionamientos que explican sus características y referentes teóricos.

No se debe obviar el marco general en el que se aprobó la Reforma Universitaria. A partir de 1961-1962 se dio un proceso de difusión masiva del marxismo en Cuba que abarcó la concienciación ideológica de la militancia, la transformación de la universidad y la formación de las nuevas generaciones en los parámetros del marxismo-leninismo. Y este objetivo se perseguía en medio de convulsas transformaciones en diversas áreas de la sociedad, la agudización de la lucha de clases y con las fricciones con Estados Unidos y un acercamiento paulatino al bloque socialista como telón de fondo.

En el caso de la filosofía, al margen de escritos puntuales de dirigentes del PSP como el de Blas Roca, ya citado, apenas se contaba con exámenes marxistas de la historia y del pensamiento cubanos ni con bibliografía actualizada sobre los problemas sociales contemporáneos y la teoría marxista. Sencillamente no se poseían suficientes recursos y bagaje para la concienciación ideológica, tal y como fue expresado en ocasiones por los dirigentes revolucionarios ${ }^{36}$. En este punto, se buscaron soluciones provisorias. La militancia del comunismo tradicional se convirtió en el principal vivero de cuadros teóricos de la Revolución. Los materiales producidos en el bloque socialista ganarían protagonismo, por cuanto incorporaban la óptica marxista y eran fácilmente asequibles gracias a las relaciones comerciales establecidas entonces con el bloque del este. Esto explica, entre otros motivos, que la mitad del profesorado de las EIR procediese del antiguo PSP $^{37}$ y que en sus cursos - previos a la Reforma Universitaria- se utilizasen ya manuales extranjeros.

Las dos grandes crisis que vivió la Revolución en 1962 no pasaron

\footnotetext{
${ }^{35}$ Entrevistas con Marta Blaquier, Niurka Pérez y A. Alonso, 13-11-17.

${ }^{36}$ Cuba Socialista, julio 1963, n. 23, pp. 51-57: GROBART, Fabio. Información sobre la Conferencia de las revistas filosóficas de países socialistas.

37 Cuba Socialista, febrero 1964, n. 30, pp. 62-77: SOTO, Lionel. Las Escuelas de Instrucción Revolucionaria en una nueva fase.
} 
desapercibidas entre los miembros del DF. Los discursos dados por Fidel Castro en marzo de ese año contra el sectarismo de las ORI y su secretario general, Aníbal Escalante, tenían oídos receptivos en una juventud a la que el dirigente le estaba indicando que no se limitase a oír y repetir, sino que desarrollase su pensamiento ${ }^{38}$.

Más sentida fue la crisis provocada por la colocación de los misiles rusos en la isla. En los testimonios del colectivo se remarca la trascendencia que tuvieron las negociaciones bilaterales entre Estados Unidos y la Unión Soviética, sin mediación cubana, así como la respuesta manifestada por el Gobierno revolucionario en un sentido de independencia y soberanía nacional. La crisis de octubre de 1962 habría dejado al descubierto cuáles eran las prioridades del campo socialista, y puso sobre la mesa la brecha existente entre la política de coexistencia pacífica defendida por la URSS y la práctica y prédica del internacionalismo revolucionario por parte del Gobierno cubano. Aurelio Alonso va más lejos aún al reflexionar sobre estos sucesos y considerar que la postura de Nikita Kruschev de pensar que los problemas los deben resolver entre "los grandes" marcó toda una década e "hizo que los sesenta fueran como fueron después, fueron escabrosos"39.

El proceso de transformación radical que vivía Cuba y el terremoto político que supuso el año 1962 abría nuevas líneas de acercamiento al marxismo-leninismo. En el caso del DF, esto conducía a una contradicción entre el paradigma filosófico sistematizado en los manuales soviéticos y la experiencia que se estaba llevando a la práctica en su propio país. El recurso a textos y al ejemplo soviéticos, si bien necesario dado el complejo escenario en el que se inició la socialización del marxismo, fue un desacierto de la Revolución en estos años, particularmente grave en el nivel universitario al partir de una tradición ajena a la cubana. Mientras que para el texto guía el marxismo-leninismo se resumía en un compendio de leyes universales, en la realidad cubana este era visto como arma teórica para la práctica de la revolución. Pese a las dudas que surgían sobre la visión plasmada en los manuales y su correspondencia con el proceso nacional, esta primera etapa careció de polémicas. Hubo una completa dedicación al trabajo y al estudio y no sería hasta el período siguiente que se dieron cuestionamientos y atisbos de renovación.

\section{Replanteamientos y debates (1964-1965)}

La segunda etapa del DF estuvo marcada por tres elementos clave: la

\footnotetext{
${ }^{38}$ En marzo y abril de 1962, Fidel Castro criticó públicamente y en varias ocasiones a las ORI y a su secretario general por haber favorecido a figuras próximas al comunismo tradicional (al PSP) y practicar, así, el sectarismo. Por ese motivo, las ORI fueron eliminadas y substituidas entonces por el PURSC y, en 1965, por el PCC. Véase CASTRO, Fidel. Discurso pronunciado en el acto homenaje a los mártires del Asalto al Palacio Presidencial [en línea]. Universidad de La Habana, 13-03-1962. [Consulta: 17-08-2021]. Disponible en $<$ http://www.cuba.cu/gobierno/discursos/1962/esp/f130362e.html>; y los discursos de Fidel Castro del 16 y 26 de marzo y 11 de abril de 1962, recompilados en BELL LARA, José; LÓPEZ GARCÍA, Delia L. y CARAM LEÓN, Tania (comps.). Documentos de la Revolución Cubana, 1962. La Habana: Editorial de Ciencias Sociales, 2009, pp. 204-213, 214-270, 271-297.

${ }^{39}$ Entrevista con A. Alonso, 13-11-2017. Sobre la influencia de la crisis de octubre en el DF véase el testimonio de F. Martínez Heredia en SUÁREZ SALAZAR, Luis y KRUIJT, Dirk. La Revolución Cubana en Nuestra América: el internacionalismo anónimo. Panamá: Ruth Casa Editorial, 2015, pp. 703-729.
} 
substitución de Luis Arana como director en diciembre de 1963, la reunión que el grupo mantuvo en febrero de 1964 con el presidente de la República Osvaldo Dorticós y los debates suscitados en el seno de la Revolución. Estos elementos condujeron a replantearse el enfoque de la enseñanza del marxismo-leninismo durante los próximos años.

A finales de 1963, se produjo la substitución del intelectual socialista Juan Marinello al frente del Rectorado de la UH, por Juan Mier Febles, antiguo miembro del PSP. Casi coincidente con este cambio, Arana dejó la dirección del DF y en enero de 1964 fue nombrado substituto Gaspar Jorge García Galló, filósofo y exmilitante también de aquel partido.

Las motivaciones detrás de este relevo no están claras. En su investigación, L. Martínez Pérez apunta que Luis Arana habría sido destituido por haber devaluado en sus clases la figura de José Martí, prócer de la independencia cubana en el siglo XIX. El colectivo de filosofía habría negado esta acusación y se habría opuesto a la remoción de Arana al frente del DF y al nombramiento de un nuevo director ${ }^{40}$.

En nuestra investigación no hemos confirmado esta hipótesis. Los datos recopilados apuntan, por un lado, a problemas de salud que aquejaban a Luis Arana $^{41}$. Por el otro, inciden en que Juan Mier Febles habría llegado al Rectorado con el propósito de sacar a los hispanosoviéticos de los lugares de responsabilidad y designar en su lugar a cubanos, puesto que se habría considerado que se daban las condiciones para que el DF estuviese dirigido por un cuadro nacional ${ }^{42}$. Esta interpretación es plausible si se tiene en cuenta que la Revolución cubana se adentró en estos años en un proceso de debate y renovación en clave nacional, dirigido al establecimiento de un socialismo independiente y respetuoso con sus raíces.

Aunque circulan distintas versiones sobre el cambio en la dirección, existe consenso en que García Galló no fue gratamente bienvenido por parte del colectivo. Los testimonios inciden en que, pese a sus apreciables capacidades pedagógicas y trayectoria militante, no era la persona adecuada para estar en el cargo ${ }^{43}$. Fernando Martínez Heredia señaló que no cumplía totalmente con la responsabilidad, de ahí que comenzaran a buscar canales alternativos a la dirección ${ }^{44}$. Isabel Monal, en cambio, achaca la hostilidad del colectivo hacia García Galló a cuestiones políticoideológicas. Hoy en día reconoce su nombramiento como un gran error, "porque la mayoría de los compañeros del Departamento tenían un rechazo muy fuerte hacia el primer Partido Comunista", el antiguo PSP, al cual aquel pertenecía. Otros testimonios confirmaron que García Galló proyectaba una visión de la filosofía y unas tareas diferentes a la que estaba defendiendo el Departamento y discordantes con las que las autoridades revolucionarias les propondrían, como veremos más

\footnotetext{
${ }^{40}$ MARTÍNEZ PÉREZ, Liliana. Los hijos de Saturno... Op. cit., pp. 102-103.

${ }^{41}$ Entrevista con Aurelio Alonso, 13-11-2017.

42 ALONSO, Aurelio. Perder y ganar en el juego de la vida. Fragmentos de un borrador de libro en proceso de redacción. Interpretación avalada también por Marta Blaquier en nuestra entrevista.

${ }^{43}$ Entrevistas con Rolando Rodríguez y Aurelio Alonso, 13-11-2017.

${ }^{44}$ MARTÍNEZ PÉREZ, Liliana. Los hijos de Saturno... Op. cit., p. 103.
} 
adelante $^{45}$

A la designación de García Galló al frente del DF le siguió una crisis de autoridad en la que el nuevo director era cuestionado y en la que parte del colectivo comenzaría a buscar canales alternativos. Fernando Martínez Heredia confesó que le hicieron la guerra internamente y que, a través del Consejo de Dirección, fueron conquistando espacios en el grupo ${ }^{46}$. Ante esta situación García Galló habría descansado cada vez más responsabilidades en la figura de Rolando Rodríguez, quien había pasado a integrar el Consejo de Dirección y acabó siendo nombrado subdirector hacia 1965. De modo que, si bien García Galló fungió al frente de la dirección hasta 1966, durante esta etapa Rolando Rodríguez sería el que habría dirigido oficiosamente la institución ${ }^{47}$. Este semivacío de autoridad permitirá una mayor flexibilidad para debatir y abrir alternativas teóricas y metodológicas en la enseñanza del marxismo.

El segundo elemento que habíamos citado como clave en esta segunda etapa es la reunión que mantuvo el colectivo con el presidente de la República Osvaldo Dorticós. Sobre los factores que condujeron a su celebración el 20 de febrero de 1964 también existen distintas opiniones. Algunos de los docentes la vinculan a la oposición suscitada en el grupo ante el nombramiento de García Galló ${ }^{48}$. En la medida en que este no era aceptado, se habría abierto una especie de interregno en la dirección que sólo se habría solucionado mediante la celebración de esta reunión con representantes del Gobierno y la universidad. Otras fuentes no recuerdan conexión entre estos dos sucesos, los cuales describen como correlativos, pero no vinculados ${ }^{49}$.

El 20 de febrero de 1964 visitaron el DF el presidente Osvaldo Dorticós y Armando Hart, ministro de Educación, quienes se reunieron con miembros del colectivo y otras autoridades universitarias. En las actas consultadas no aparece un listado completo de los asistentes, sólo de las personas que intervinieron oralmente ${ }^{50}$. Aparte de Dorticós y Hart, estaban presentes al menos: Juan Mier Febles (rector de la UH), Mariano Rodríguez Solveira (vicerrector docente de la

\footnotetext{
${ }^{45}$ Entrevista con Marta Blaquier. En nuestra entrevista, Thalía Fung alabó la formación filosófica de García Galló, pero aclaró que "no era como la de otros", evidenciando así las tendencias.

${ }^{46}$ MARTíNEZ PÉREZ, Liliana. Los hijos de Saturno... Op. cit., p. 103. Según Martínez Heredia, se estableció el Consejo de Dirección al ser nombrado director García Galló, "para ayudarlo a él, supuestamente, y para hacerle la guerra de una manera legal, pero semiclandestina": Ibídem. No obstante, como se ha comentado, este existía desde 1963. Cuando entró García Galló en la dirección, fue ampliado. Rolando Rodríguez y Ricardo Jorge Machado al menos pasaron a ser miembros.

${ }^{47}$ Entrevista con Rolando Rodríguez.

${ }^{48}$ Entrevistas con Marta Blaquier, Rolando Rodríguez y A. Alonso, 27-11-2017; y testimonios de Martínez Heredia en MARTÍNEZ PÉREZ, Liliana, Los hijos de Saturno... Op. cit., pp. 103-104.

49 Entrevistas con Niurka Pérez e Isabel Monal. En la documentación tampoco hemos avistado relación.

50 Hemos consultado las actas de esta reunión en DPNP: Actas de la reunión del DF con Osvaldo Dorticós y otras autoridades, s. tít., 20-02-1964, 43 pp. Las referencias en las siguientes páginas remiten a este documento. Parte del discurso de Dorticós en esta reunión se publicó en: BELL LARA, José; LÓPEZ GARCÍA, Delia L. y CARAM LEÓN, Tania (comps.). Documentos de la Revolución Cubana, 1965. La Habana: Editorial de Ciencias Sociales, 2013, pp. 382-420.
} 
misma institución) y Rebellón ${ }^{51}$ por parte de las autoridades universitarias; Gaspar García Galló (director del DF) y los docentes Jesús Díaz, Aurelio Alonso, Ramón Solá, Rolando Rodríguez, Isabel Monal, Juan Guevara, Ricardo J. Machado y Ariel Barreiras Enrich por parte del DF. Habrían asistido también el resto de los profesores, aunque no intervinieron.

A grandes rasgos, los desafíos abordados fueron los siguientes: a) déficit de cuadros teóricos en el movimiento revolucionario cubano; b) tareas y metas del DF; c) actualización de bibliografía y materiales de estudio; d) necesidad de ampliación del personal docente; e) programa de la asignatura Materialismo Dialéctico y Materialismo Histórico; f) renovación de los métodos pedagógicos y los objetivos de la enseñanza; g) orientación por parte del Partido y las autoridades universitarias; h) adaptación del marxismo-leninismo a la realidad nacional.

Los profesores del Departamento expresaron inquietudes en torno al programa docente y su especialización; la urgencia por ampliar la plantilla; la carencia de materiales de estudio y la ausencia en Cuba de bibliografía actualizada sobre filosofía, marxismo-leninismo y ciencias sociales. Las dificultades para consultar obras de Hobbes, Kant o Hegel fueron algunos ejemplos que citaron. Por último, el DF solicitó orientación de la dirección al no saber qué responder ante temas controvertidos de la historia reciente de Cuba, caso de las polémicas culturales suscitadas en 1963 alrededor del realismo socialista.

La mayor cantidad de espacio se reservó a las orientaciones de Osvaldo Dorticós. El presidente respaldó su discurso con un enfoque general frente a las deficiencias que vivía Cuba ante el proceso de orientación ideológica y de construcción del socialismo. Comenzó haciendo un estado de la cuestión sobre la recepción del marxismo-leninismo en Cuba a la llegada de los revolucionarios al poder. De algún modo contextualizó las dificultades que confrontaba el DF en el marco de la escasa tradición teórica existente en la isla. Este semivacío se debía, a su parecer, a que los primeros partidos marxistas cubanos se habían desarrollado casi siempre en la clandestinidad y a que el Partido de la Revolución era de reciente creación, integrado por viejos marxistas, pero especialmente por trabajadores, estudiantes, intelectualidad de "innegable decisión revolucionaria", pero de "un general bajo nivel teórico".

La adhesión masiva al socialismo por parte de la población no habría sido producto de una enseñanza teórica previa. Antes bien, y sin menospreciar el bagaje marxista acumulado, se habría dado como fruto "de la realización factual revolucionaria", particularidad que había generado un déficit teórico a la Revolución. De ahí que se propusiese la formación de profesores a través del propio ejercicio de la docencia, experiencia que se había visto multiplicada en numerosas facetas nacionales.

Dorticós instó al colectivo a emprender una renovación de los materiales y los instrumentos pedagógicos. La aspiración del DF debía ser la más estrecha

\footnotetext{
${ }^{51}$ Aunque no aparece el nombre, puede que se trate de José Rebellón, presidente de la Federación Estudiantil Universitaria (FEU) entre 1962 y 1964.
} 
vinculación con el medio social cubano y su realidad histórica revolucionaria. La dirección de la Revolución demandaba cambiar el abordaje de la enseñanza del marxismo-leninismo y promover un punto de referencia cubano, un enfoque que entonces escaseaba:

\begin{abstract}
"Estamos superando ya el mal del manualismo. Es decir, muchas veces el aprendizaje del marxismo-leninismo en los institutos de nuestro país, se ha hecho a través de los manuales que hemos recibido, y que se han difundido a veces esto es culpa nuestra fundamentalmente- de una manera masiva, sin un rigor previo y sin examinar mucho el contenido de esos manuales. Manuales que inclusive en el país de origen, pues, son objeto de polémicas, de ataques, de impugnaciones; no son manuales aceptados de manera ortodoxa por la Dirección del Partido ni mucho menos, pero que además están conformados a una realidad histórico-social concreta -son manuales soviéticos casi todos ellos, o todos ellosque es la realidad histórico-social de la Unión Soviética. Y nosotros debemos conformar la enseñanza del marxismo-leninismo fundamentalmente -sin perder de vista desde luego la realidad universal-, a nuestra realidad histórico-social concreta, a la cubana. Y para eso no existe ningún manual. De ahí que ustedes tengan que hacer un gran esfuerzo intelectual y un trabajo realmente de creación [...]. A nuestro juicio y para la Dirección del Partido y del Gobierno lo más importante es no que ustedes enseñen en forma memorística el marxismoleninismo a los alumnos, ni que enseñen dogmas ni axiomas que no existen dentro del marxismo, sino compañeros, que ustedes enseñen a pensar a los alumnos [...]. Teniendo en cuenta además que el marxismo-leninismo es una ciencia que está en continuo desarrollo, y por consiguiente, dentro de los estudios del marxismo leninismo caben interrogaciones, caben dudas y caben inquietudes intelectuales" ${ }^{\prime 2}$.
\end{abstract}

El manualismo se identificó como un error cometido por la Revolución cubana y del cual habría que despegarse. Los motivos para este rechazo eran dos: por un lado, los manuales tomaban como punto de partida una realidad histórico-nacional socialista, pero ajena al contexto revolucionario cubano; por el otro, se establecía una correspondencia entre el manual, un método de enseñanza memorístico y la sistematización de la teoría marxista bajo dogmas generales que, en vez de servir como guía para la acción, imponían una camisa de fuerza al estudiantado.

Dorticós reconoció la escasez de bibliografía actualizada -generalizada en todas las disciplinas- y adelantó que se estaban emprendiendo iniciativas en esta dirección. Aun así, animó al colectivo de docentes a desprenderse de los manuales, siempre que las circunstancias lo permitiesen. Frente al binomio manualismomemorismo, el Gobierno revolucionario alimentó el desarrollo intelectual a la luz de un marxismo creador que incentivase un proceso de razonamiento y comprensión por parte de los universitarios. La labor del colectivo habría de aspirar a que el alumnado proyectase una inquietud intelectual, plantease problemas y desarrollase "su capacidad de pensar y de razonar por sí mismo, con un sentido crítico".

Esta vocación en la enseñanza del marxismo no había prevalecido en Cuba en los últimos años, a causa de "inexperiencia", "inercia mental" y "rutina". El presidente

52 DPNP: Actas de la reunión del DF con Osvaldo Dorticós y otras autoridades, s. tít., 20-02-1964, pp. 19-20. 
aludió a los estudios de economía política como modelo pedagógico desacertado, explicados fundamentalmente a partir del Manual de la Academia de Ciencias de la Unión Soviética, al cual calificó como "esencialmente deficitario". Su uso y el método de enseñanza seguido habían conducido a que los recién iniciados entendiesen sus contenidos como verdades marxistas irrebatibles. Algunas prácticas y métodos de organización económica avalados en algunos países socialistas se habían elevado a la categoría de leyes fundamentales del marxismo. Para el presidente, en cambio, era imperativo distinguir entre principios centrales y formulaciones teóricas. En estas últimas había cabida para diferentes posiciones en función del contexto nacional y sin que ello derivase en una desviación del pensamiento marxista.

Esta alusión conectaba con el Gran Debate (1963-1964) que tuvo lugar en Cuba durante estos años en torno a los métodos de gestión y planificación económica, en el cual Ernesto Guevara perseguía proponer su propio modelo de transición socialista. El Manual de la Academia de Ciencias de la URSS favorecía el cálculo económico frente a la planificación, defendida por el argentino. Si se comparan las críticas que Dorticós hizo en esta reunión al manual con las que el Che plasmó por escrito, se puede corroborar la similitud de enfoques ${ }^{53}$.

Como contrapunto a los manuales, el presidente enfatizó la importancia de estudiar a los clásicos: en vez de depender de interpretaciones elaboradas a posteriori por este o aquel otro autor, aconsejó entrar en contacto con los principales pensadores de cada época. Sólo así lograrían un método eficiente de razonamiento y de estudio. Acompañando a los clásicos, propuso incluir una explicación de la historia cubana y una revalorización de su pensamiento filosófico, sobre todo a partir del siglo XIX. El enfoque nacional era crucial para evitar que las generaciones futuras creyesen que la historia de Cuba había comenzado tan solo unos años antes.

Esta renovación pedagógica implicaba una necesaria vinculación con la dirección política. La enseñanza del marxismo-leninismo debía tener carácter partidista y adecuarse a los objetivos y lineamientos de la Revolución. Esta orientación era necesaria sobre todo ante temáticas que suscitaban polémica durante esos años. Los profesores habían solicitado consejo para responder sobre las polémicas en la cultura en 1963 en torno al realismo socialista o sobre el proceso de unificación de las fuerzas revolucionarias tras el triunfo en 1959. Respecto al primer tema, el presidente aclaró que se podía tener distintas opiniones al respecto sin violar el marxismo:

“...este es uno de los riesgos que corre la enseñanza del Marxismo a que yo me refería hace un momento- sabemos que los problemas estéticos, desde el punto de vista marxista son muy polémicos en el mundo; ahora, lo que se olvidó durante un tiempo es que no existía la estética marxista-leninista, y que ni Marx, ni Engels ni Lenin tuvieron oportunidad ni posibilidad de desarrollar una estética marxistaleninista. $Y$ entonces algunas frases sueltas, algunas formulaciones un poco esquemáticas y algunos criterios, por razón casi bibliográfica, porque se reunieron

\footnotetext{
${ }^{53}$ GUEVARA, Ernesto. Apuntes críticos a la economía política. La Habana: Ocean Sur, 2006, pp. 61218. Tienen especial interés las páginas 173-177. Sobre el Gran Debate véase YAFFE, Helen. Che Guevara: the economics of revolution. London: Palgrave Macmillan, 2009, pp. 45-69.
} 
en un libro un día, en otras ocasiones porque se proclamaron como verdades definitivas del marxismo, comenzaron a convertirse en dogma, cuando en realidad hoy en todos los países socialistas esos problemas [...] de la estética son problemas muy polémicos" $"$.

También las transformaciones últimas de la ciencia, la revolución técnica y científica a nivel mundial habían impuesto nuevos retos a la dialéctica de la naturaleza y al marxismo-leninismo. El campo de la estética y las ciencias naturales fueron dos ejemplos mencionados por Dorticós para demostrar el potencial que aún quedaba por explotar dentro de la teoría marxista. Al apelar a ellos, el presidente reforzaba el espíritu crítico con el que habían de trabajar los profesores: bajo los parámetros de los principios marxistas, pero induciendo al estudiantado y a ellos mismos a la reflexión y a la no aceptación de un pensamiento dogmatizado.

Dorticós recalcó la relevancia de que el DF tuviese canales para ventilar inquietudes y conocer el criterio de la dirección política. Diversas problemáticas habían sido abordadas en discursos de Fidel Castro. Estos podían ser llevados a clase, dándole un carácter vivo a la enseñanza, sin tener inclusive "muchos escrúpulos en conservar rígidamente un programa”. El fin era el razonamiento argumentado, no la interiorización dogmática.

"Yo les digo que hay que incendiar el Atlántico, iy ustedes miren a ver cómo lo incendian!": esta es la frase pronunciada por Dorticós que a menudo se cita como conclusión de este encuentro. Sin embargo, lo dicho en las páginas anteriores evidencia un debate de mayor trascendencia: rechazo al manualismo-memorismo, ánimo de una enseñanza crítica y viva, vuelta a los clásicos y adopción de un punto de vista nacional fueron las metas impuestas al DF.

La idoneidad de usar manuales extranjeros o no había sido motivo de preocupación desde el momento en el que se aprobó la Reforma Universitaria. Ya entonces algunos intelectuales cubanos apuntaron a distinguir los socialismos soviético y cubano ${ }^{55}$. Durante estos años, la dirección política alertaría en varias ocasiones sobre el peligro de apegarse excesivamente a esquemas preconcebidos. Se puede citar el discurso dado por Fidel Castro en 1963 en un acto de graduación de las Escuelas Básicas de Instrucción Revolucionaria. En él, al mencionar los avances en la socialización del marxismo-leninismo, aprovechó para recordar que era necesario esquivar aquellas interpretaciones que presentaban su teoría como un conjunto de "formulitas" mecánicas para tratar de aplicar a la fuerza a la explicación de cada problema concreto ${ }^{56}$. Otro ejemplo, aunque no público, fueron las demoledoras críticas que Guevara escribió sobre los manuales soviéticos en $1965^{57}$.

${ }^{54}$ DPNP: Actas de la reunión del DF con Osvaldo Dorticós y otras autoridades, s. tít., 20-02-1964, p. 25.

${ }^{55}$ Citado en GUANCHE, Julio C. El continente de lo posible... Op. cit., p. 66.

${ }^{56}$ CASTRO, Fidel. Discurso pronunciado en las conclusiones del Primer Congreso Nacional de Maestros de Vanguardia "Frank País", conjuntamente con el acto de graduación de las EBIR [en línea]. La Habana, 10-04-1963. [Consulta: 17-08-2021]. Disponible en <http://www.cuba.cu/Gobierno/discursos/1963/esp/f100463e.html>.

${ }^{57}$ Formuladas en una carta enviada a Armando Hart, 4-12-1965: "en Cuba no hay nada publicado, si excluimos los ladrillos soviéticos que tienen el inconveniente de no dejarte pensar; ya el partido lo hizo por ti y tú debes digerir. Como método, es lo más antimarxista, pero, además suelen ser muy 
Al margen del Gobierno, existían otras voces en desacuerdo con el carácter de la enseñanza marxista-leninista en Cuba. Conocemos críticas similares al trabajo realizado, en este caso, por el Departamento de Filosofía de la Universidad de Oriente (Santiago de Cuba) ${ }^{58}$. A pesar de que no consta la data ni la autoría oficial, se pueden anotar dos pistas sobre este documento: primero, se puede situar entre 1963-1964; segundo, en dos páginas aparece escrito a mano el nombre Alessandro Mazzone. En su momento, intentamos -sin éxito- contrastar su posible autoría. Aunque no está confirmada, esta hipótesis es posible si se tiene en cuenta que este filósofo italiano visitó Cuba en $1963^{59}$.

Este documento era un informe valorativo de la enseñanza del marxismoleninismo por parte del Departamento de Filosofía de la Universidad de Oriente, formado por cinco profesores ${ }^{60}$. El contenido de las críticas realizadas a su trabajo compartía el mismo espíritu que las pronunciadas por Dorticós acerca del DF de La Habana. En el informe, la persona firmante reprobaba que en el programa de filosofía marxista apenas hubiese referencias a la cultura e historia cubanas. Como solución, instaba a los docentes a aproximarse a la vida y cultura nacional y a rechazar la falsa idea de que el producto de segunda calidad era bueno para empezar. Más aún, en el documento se condenaba que se explicase la dialéctica como "sistema de leyes puras" sin mencionar las contradicciones en los sesenta entre socialismo e imperialismo, y que se ofreciese una visión abstractamente teórica y sistémica del marxismo, puesto que conducía a un "doctrinarismo" en el que los conceptos se enseñaban "mecánicamente", como "fórmulas muertas". Dos consecuencias básicas se derivaban de este enfoque: la memorización sin elaboración del pensamiento por los estudiantes y la tendencia a considerar el marxismo como un conjunto de recetas que servían para solucionar cualquier problema de la ciencia y la sociedad. En definitiva, el fin último de la enseñanza no era convencer para convertir, sino educar para construir. Según este informe, el Partido tenía pendiente reunirse con el Departamento de Filosofía de Oriente. Desconocemos si esto se llevó a cabo y si orientaciones como las que Dorticós ofreció al DF de La Habana también fueron recibidas en Las Villas y Oriente.

El tercer elemento definitorio en esta etapa fue el contexto que vivía Cuba. En su estudio sobre el proceso revolucionario en la isla, A. Kapcia argumenta que la existencia de debates y crisis periódicas fueron claves para el proceso de cambio y adaptación de la Revolución y para su supervivencia. Una de estas crisis se desencadenó, según este autor, desde $1962^{61}$. Los sucesos de ese año, en lo nacional e internacional, fueron seguidos por un período de intensos debates

malos". Carta consultada en GUEVARA, Ernesto. Apuntes filosóficos. La Habana: Ocean Sur, 2012, pp. 22-25.

${ }_{58}$ Archivo Histórico del Instituto de Historia de Cuba, La Habana, Fondo CC-PCC 10.1, Carpeta 36, Expediente 3, Documento 741, Folios 41-62: "Observaciones para una discusión donde la enseñanza del Marxismo en la Universidad", s. f. (ca. 1963-1964).

59 Información recogida en la página web del Partido Comunista dei Lavoratori (Italia) [en línea]. [Consulta: 17-08-2021] Disponible

en <https://www.pclavoratori.it/files/index.php?obj=NEWS\&oid=2831>.

${ }^{60}$ Acorde con el documento, estos cinco eran: Nils Castro, Nené Ibarra Martín, Doralia Menéndez, Sara Gómez y María del Carmen Rodríguez, las tres últimas formadas en la Escuela Nacional Cepero Bonilla con Luis Arana.

${ }^{61}$ KAPCIA, Antoni. Cuba in revolution... Op. cit., pp. 27-28, 34-36. 
alrededor de qué socialismo se quería para la isla, sus fuentes de inspiración, métodos de gestión económica, paradigmas culturales y posicionamiento en el tablero mundial. Tras una fase en la que la Unión Soviética había figurado como espejo al que mirar, proliferaron voces críticas ante una posible imitación del paradigma del este. Estas tendencias se dieron en diferentes ámbitos sociales. La dirección política de la isla resucitaría en adelante una reivindicación de su autoctonía y la búsqueda de un socialismo que, si bien entroncaba con la tradición comunista internacional, bebía de las raíces nacionales y debía buscar respuestas a partir del propio contexto histórico y social.

Esta fue la etapa en la que se produjeron el Gran Debate (1963-1964) sobre el sistema económico de una sociedad en transición; y las polémicas culturales en torno al dogmatismo, con argumentos a favor y en contra del realismo socialista y con especial protagonismo del campo cinematográfico ${ }^{62}$. Se dio también un retroceso político de las tendencias comunistas ortodoxas tras los sucesos en 1962 y fueron los años en los que Cuba comenzó a promocionar las guerrillas latinoamericanas y a tender puentes estratégicos con el tercer mundo, fruto de sus contactos con el Movimiento de Países No Alineados, con Argelia y con figuras destacadas en los movimientos de liberación del sur ${ }^{63}$. Aparecían, así, cuestionamientos hacia el paradigma comunista tradicional en diversos ámbitos, a la par que se descubrían otros referentes a escala internacional y se reforzaban las raíces del pensamiento y práctica nacionales ${ }^{64}$. Puestos todos los elementos sobre la mesa, el contexto que vivía la Revolución y el discurso de Dorticós ejercieron como pivotes para la renovación y cubanización de los programas de filosofía marxista.

Entre el 1 y el 3 de octubre de 1964 tuvo lugar la Primera Plenaria Nacional Universitaria de Profesores de Filosofía que reunió a los Departamentos de Filosofía de la Universidad de Las Villas, Oriente y La Habana, con sede en esta última ${ }^{65}$. En las conclusiones de esta reunión se evidencian tres novedades. Primero, se impuso como tema obligatorio el tratamiento de la filosofía y el pensamiento social en Cuba. El objetivo era adaptar los manuales y la enseñanza del marxismo a las raíces nacionales y al ejemplo de la Revolución. Segundo, se acordó seleccionar un stock de textos de los clásicos marxistas, de los próceres cubanos, dirigentes revolucionarios nacionales y del pensamiento contemporáneo que sirviese como

\footnotetext{
${ }^{62}$ Véase GUANCHE, Julio C. El continente de lo posible... Op. cit., pp. 7-72.

${ }^{63}$ Véase ALBURQUERQUE, Germán. Cuba en el Movimiento de Países No Alineados: el camino al liderazgo. Causas y motivaciones. 1961-1983. Caravelle. Cahiers du monde hispanique et lusobrésilien [en línea]. 2017, n. 109, pp. 179-193. [Consulta: 17-08-2021]. Disponible en <https://doi.org/10.4000/caravelle.2518>; y KRUIJT, Dirk; REY TRISTÁN, Eduardo y MARTíN ÁLVAREZ, Alberto (eds.). Latin American Guerrilla Movements. Origins, Evolution, Outcomes. New York: Routledge, 2020. $237 \mathrm{p}$.

${ }^{64}$ Nuestra interpretación sobre el contexto general de la Revolución en los sesenta puede verse en GONZÁLEZ LAGE, Valeria. Más allá de la isla. El rol cubano en la configuración de un imaginario revolucionario para América Latina, 1960s. En: ALCÁNTARA, Manuel; GARCÍA, Mercedes y SÁNCHEZ, Francisco (coords.). Memoria del 56ํㅡ Congreso Internacional Americanistas. Salamanca: Universidad de Salamanca, 2018, pp. 433-443.

${ }^{65}$ DPNP: "Primera Plenaria Nacional Universitaria de Profesores de Filosofía. Conclusiones.", octubre de 1964, 28 pp. La información sobre este encuentro remitirá a este documento. Sobre esta plenaria ha escrito también GONZÁLEZ ARÓSTEGUI, Mely del Rosario. Las Plenarias Nacionales... Op. cit.
} 
base de estudio y permitiese prescindir poco a poco de los manuales, uso que habría de limitarse a lo indispensable en un futuro. Y, por último, se ratificó la creación de secciones de investigaciones y la programación de actividades de superación en los Departamentos de las tres universidades.

Más relevante para el tema que nos ocupa, en esta Plenaria el DF de la UH anunció su negativa a seguir usando el manual escrito por Konstantinov como material para la enseñanza. En un informe ceñido al colectivo habanero se recogía esta decisión y se justificaba por la influencia que habían tenido en el grupo las orientaciones ofrecidas por Osvaldo Dorticós unos meses antes. Se iniciaba así un cambio en el abordaje de la filosofía marxista y la búsqueda de una perspectiva nacional, en línea con el discurso del presidente.

Para el curso 1964-1965, el DF de La Habana eliminó el manual soviético como material básico de enseñanza. Desechado este recurso pedagógico y conscientes de las metas que la dirección de la Revolución les había propuesto, el profesorado se embarcó en los años posteriores en una intensa búsqueda y renovación de las bases sobre las que enseñar la filosofía marxista. El paso dado era significativo, pero estaba sustentado en un criterio de negación hacia el manualismo. En estos momentos no se contaba con materiales docentes ni un esquema pedagógico que sirviese como substitución:

\begin{abstract}
"Era ahora la dirección de la Revolución quien nos demostraba, de golpe, lo lejos que estábamos aún de lo que se esperaba de nosotros. Esa visita decretó la muerte del manualismo. Dorticós nos invitó a quemar el océano. Su intervención mimeografiada fue discutida en todos los grupos durante semanas de modo verdaderamente febril. Como no habíamos logrado acumular una cultura revolucionaria, nos lanzamos a una búsqueda con pico de barro. Sabíamos lo que no debíamos hacer, y un poco más: volver con fuerza y aplicación verdaderamente escolares al estudio de los clásicos. Fue una de las etapas más críticas y creadoras de nuestra pequeña historia, allí se generaron también muchos de nuestros errores. Liquidamos textos y programas, pero no dimos, no podíamos dar, nada orgánico a cambio. Se experimentó en todas direcciones y se erró en muchas. Virtualmente cada profesor construyó su propio programa y dijo lo que buenamente pensaba"66.
\end{abstract}

Al abandono del manual escrito por Konstantinov, le siguió una especie de vacío teórico y heurístico. Para poder avanzar, a la negación habría de sucederle un período de creación, so pena de estancamiento o limitación a un simple movimiento de crítica. Esta sería una etapa de búsqueda en todas las direcciones, especialmente en cuatro ámbitos: 1) la adopción de esquemas y técnicas pedagógicas tendientes al análisis crítico y no al memorismo; 2) foco de atención en los clásicos y en la mejora de la formación intelectual; 3) la diversificación bibliográfica y 4) la renovación de los programas presentada a la vez como fin y efecto de todo lo anterior.

\footnotetext{
${ }^{66}$ DPNP: "Esquema de la evolución del Departamento de Filosofía de La Universidad de La Habana", s.f. (ca. 1970-1971), 14 pp.
} 
Ya a inicios de los sesenta la dirección cubana había recomendado no fundamentar la enseñanza sobre exámenes tradicionales ni depender de la capacidad de memorización del alumnado ${ }^{67}$. En esta línea y animados por la reunión con el presidente, el DF ensayó nuevos métodos de evaluación. Rolando Rodríguez recuerda haber preguntado en una prueba cómo se podía interpretar, a la luz de la filosofía marxista, lo que Marx había escrito en cuanto a base y superestructura. Lo que se perseguía era una interpretación analítica acorde a la comprensión del alumnado. Según explicó en nuestra entrevista, significaba "use su cabeza y dígame qué quiso decir Marx".

Durante los cursos 1964-1965 y 1965-1966 el DF se dedicó a confeccionar un programa propio, que supliese al anterior y reformase el esquema del Konstantinov. Las lecturas y la superación adquirieron entonces una trascendencia particular, por cuanto emergían como una fórmula urgente y eficaz para la búsqueda de alternativas pedagógicas y teórico-metodológicas. En primer lugar, el abandono del manualismo condujo al análisis de los clásicos del marxismo. Las lecturas de Marx, Engels y Lenin realizadas en la primera etapa se multiplicaron en estos dos años para adquirir un conocimiento de la teoría marxista por contacto directo con los que habían sido sus principales pensadores. El manual tuvo en los clásicos su principal substituto, cuyas obras eran mecanografiadas en el colectivo, discutidas y entregadas como material básico al alumnado.

El DF se insertaba de este modo en una corriente global caracterizada por una "vuelta a Marx" y el rescate de las obras de los fundadores del marxismo como vacuna contra la dogmatización y la tergiversación de su teoría durante el estalinismo. Sin embargo, lo que para los círculos intelectuales de izquierda significaba una "recuperación", para el colectivo de La Habana suponía casi una revelación. Docentes de reciente y acelerada formación, en estos años se acercaban a los clásicos aún por primera vez. El acceso a Marx, Engels y Lenin se realizaba por la necesidad de profundización en una teoría que debía ser transmitida críticamente al alumnado y estructurada en un programa aún en proceso de construcción.

Aparte del debate sistemático en torno a los clásicos, se continuó con los seminarios sobre historia de la filosofía y lógica impartido por Justo Nicola. A raíz de este último, un pequeño número de profesores fueron formados en lógica $y$, mediados los sesenta, se dio el salto con la introducción de esta materia en la docencia universitaria ${ }^{68}$. Otros seminarios organizados versaron sobre el desarrollo del pensamiento de Lenin y sobre las Revoluciones rusas de 1905 y 1917; la Teoría del Conocimiento en Renato Descartes; el pensamiento marxista o el Joven Marx (análisis del origen del marxismo y de las obras previas a La Sagrada Familia).

\footnotetext{
${ }^{67}$ DORTICÓS, Osvaldo y HART, Armando. Mensaje educacional al pueblo de Cuba. La Habana: Ministerio de Educación de Cuba, 1960, pp. 79-82.

${ }^{68}$ En el currículum de Niurka Pérez (mostrado por esta en nuestra entrevista) se sitúa en 1965 el inicio de la enseñanza de lógica por parte del DF. El grupo de lógica se convertiría a fines de los sesenta en una de las células de especialización del colectivo, con programas y plan de superación propios.
} 
Otros alicientes a la formación del profesorado vinieron de la mano de privilegios concedidos por la Universidad. En este período se le permitió al DF cursar una carrera universitaria o asignaturas correspondientes a distintas carreras, sin la obligación de completar todo su plan de estudios. Más aún, a partir de la Primera Plenaria Nacional (octubre 1964), se permitió el traslado de profesores a otras universidades para cursar determinadas materias y la asistencia a seminarios, círculos de estudio, etc. ofertados por otras escuelas universitarias. Gracias a este privilegio tuvieron acceso a una formación interdisciplinar y flexible que satisfacía las inquietudes intelectuales personales, permitía establecer una afinidad entre la filosofía marxista y las disciplinas con las que se relacionaba la docencia y encontrar soluciones a los retos planteados por la dirección política. Esta flexibilidad institucional repercutió positivamente en su formación y suponía cierto privilegio frente a otros grupos intelectuales cubanos situados dentro y fuera de los muros de la colina universitaria.

Otra novedad reseñable en esta etapa "experimental" es la referida a la diversificación bibliográfica. Este paso adelante se dio por necesidad, como recurso alternativo al manualismo; y por oportunidad, como resultado de la difusión de diversos autores en Cuba. La política editorial de la isla en estos años cosechó éxitos notables si se tienen en cuenta las deficiencias materiales y comerciales existentes. Fueron apareciendo numerosos referentes internacionales, primero a través de ediciones extranjeras, luego cubanas.

Asumieron en este período escritos de otros pensadores marxistas, como S. T. Meliujin, Adam Schaff o Roger Garaudy. Los dos primeros se conocieron a través de ediciones extranjeras primero, luego cubanas; mientras que el último gozó de gran difusión tras su estancia en la isla en 1962, publicándose más de cinco trabajos suyos entre 1959 y 1965 . Estos autores, citados en la programación de la materia entre 1963 y 1965, quedaron relegados a un relativo segundo plano después, por entender que su respuesta al dogmatismo en filosofía era "políticamente de derecha" 69 .

Autores clásicos apenas conocidos anteriormente u otros en boga en los sesenta emergieron como referencia teórica para parte de la intelectualidad cubana. Se constatan así nuevas miradas sobre la contemporaneidad que conectaban con tres fuentes principales: el pensamiento revolucionario cubano, especialmente desde el siglo XIX; los movimientos de liberación nacional y antiimperialistas emergentes en los sesenta; por último, las contribuciones más recientes en torno a la teoría y metodología marxistas y las ciencias sociales en general. Para el DF, enriquecer el bagaje disponible representaba un factor de corrección del dogmatismo y una enmienda al vacío creado por su rechazo al manualismo.

En primer lugar, se introdujo con fuerza la mirada nacional. En la reunión con Dorticós se había trasladado la preocupación de la dirección por incorporar la historia de Cuba y rescatar su pensamiento filosófico. Entonces, ganaron presencia

\footnotetext{
${ }^{69}$ DPNP: Historia y evolución del Departamento de Filosofía y Pensamiento Crítico, s. tít., s.f. (post 1971), 7 pp. Véase también la revista Casa de las Américas, La Habana, n. 33, noviembre-diciembre 1965, pp. 135-140: DÍAZ, Jesús. Adam Shaff y la filosofía del hombre.
} 
los análisis y lecturas de José Martí, Enrique J. Varona, Fernando Ortiz, Julio Antonio Mella o El Ingenio, de Manuel Moreno Fraginals. De hecho, en este período de experimentación, el objetivo del DF no fue romper con la estructura sistémica de los manuales. Su meta básica fue la cubanización de sus contenidos, la utilización en las aulas de ejemplos y textos nacionales y entroncar el DIAMAT e HISMAT con las que habían sido las raíces más destacadas de la Revolución de 1959: los pensadores del siglo XIX y de la Revolución de $1930^{70}$. La formación de la identidad cubana, el ejemplo de las luchas independistas y la Revolución de 1930, el ideario de sus promotores, la estructura socioeconómica de la República neocolonial, la unificación de las fuerzas revolucionarias en la lucha contra Fulgencio Batista o la construcción del socialismo en la isla fueron elementos que comenzaron a ser atendidos paulatinamente por el colectivo. Este fenómeno de "repensar la nación" daría lugar en el DF a un grupo que, en la segunda mitad de los sesenta, se especializará en pensamiento revolucionario cubano, con planes de estudio, investigación y superación propios.

En segundo lugar, la sensibilidad manifestada por la dirección cubana con la liberación nacional y el fenómeno tercermundista tuvo su reflejo en la política de difusión editorial y cultural. Se divulgaron en la isla autores que plasmaban una corriente antiimperialista, caso de José Carlos Mariátegui (publicado en Cuba en 1963), Patricio Lumumba (1964), Frantz Fanon (1965) o Mao Tse-Tung, de quien circularon hasta seis títulos entre 1963 y 1964. A estos se les añadía los numerosos discursos pronunciados por los dirigentes cubanos a favor del internacionalismo revolucionario y la urgencia de la Revolución en los llamados países subdesarrollados.

En tercer lugar, al estudio intensivo de Marx, Engels y Lenin, habrían de añadírsele lecturas de las aportaciones marxistas creadas en la primera mitad del siglo XX y aquellas otras más contemporáneas que perseguían una interpretación de su teoría acorde a la realidad vigente. Como apuntó J. Ortega, la recepción de estas perspectivas renovadas conectaba con la posibilidad de romper con aquellas ortodoxas soviéticas, notablemente divulgadas en los espacios de producción cubanos en años previos ${ }^{71}$.

Nos referimos a la circulación de G. Lukács, A. Gramsci o Louis Althusser, por ejemplo. De este último, la Editorial Venceremos publicó en 1964 Contradicción y superdeterminación (Notas para una investigación). La diferencia entre Marx y Engels y la propuesta de un "corte epistemológico" en la evolución intelectual del primero tendrán un apreciable impacto en el DF, positivo en un primer momento, y

\footnotetext{
${ }^{70}$ Testimonio de A. Alonso, quien reconoce la dificultad de vincular harmónicamente el DIAMAT e HISMAT de los manuales con el bagaje nacional, recogido en GONZÁLEZ ARÓSTEGUI, Mely del R. Las plenarias... Op. cit., p. 69. Sobre esta fusión véase KAPCIA, Antoni. A short history of revolutionary Cuba: Revolution, Power, Authority and the State since 1959. London: Bloomsbury Publishing, 2021, p. 5-ss.

${ }^{71}$ ORTEGA REYNA, Jaime. Incendiar el océano. Notas sobre la(s) recepción(es) de Althusser en Cuba. De Raíz Diversa. Revista especializada en estudios latinoamericanos [en línea]. 2015, vol. 2, n. 4 , pp. 129-153. [Consulta: 17-08-2021]. Disponible en $<$ https://biblat.unam.mx/hevila/Deraizdiversa/2015/vol2/no4/5.pdf>.
} 
crítico en años posteriores $^{72}$. Los Cuadernos de la Cárcel de Antonio Gramsci fueron llegando a la isla antes de 1965, a través de los llamados "libros verdes", la versión publicada en Argentina entre 1958 y 1962 por la Editorial Lautaro ${ }^{73}$. EI DF introdujo el pensamiento gramsciano en sus programas y lecturas y reprodujo fragmentos mimeografiados para ser analizados tanto por el profesorado como el alumnado. Del comunista italiano acogieron, entre otros elementos, su historicismo y defensa de la contextualización social de todo pensamiento, el concepto e implicación de la filosofía de la praxis, la consideración del comunismo como proceso de transformación integral y el rol que en este se le reservaba a la intelectualidad ${ }^{74}$.

A las interpretaciones de Gramsci, Lukács o Althusser, se le irían añadiendo las de Galvano Della Volpe, Auguste Cornú, Nicola Abbagnano o Rosa Luxemburgo, entre otras, a medida que eran publicadas. El DF consiguió un mimeógrafo para su sede en la Calle K, sita en El Vedado. Este aparato permitió al colectivo reproducir una gran variedad de fragmentos de obras, discursos y escritos tanto internacionales como de dirigentes cubanos. En él imprimieron fragmentos de Cuadernos de la cárcel de Gramsci, textos de Marx, Engels y Lenin, Moncada: el primer combate de Fidel Castro escrito por el francés Robert Merle o el histórico discurso pronunciado por Ernesto Guevara en Argel el 24 de febrero de 1965 y en el que criticaba públicamente la pasividad del movimiento comunista internacional ante los procesos de liberación en el tercer mundo, en especial ante la intervención imperialista en Vietnam.

Es justo reconocer que el DF fue un protagonista más de un fenómeno nacional y global signado por el rescate de marcos teóricos antaño arrinconados por la tradición comunista internacional y por el descubrimiento de las respuestas más actuales ante la dogmatización del marxismo. En el caso de Cuba, Casa de las Américas, la Unión de Escritores y Artistas de Cuba u otra intelectualidad destacada también contribuyeron a la difusión de nuevas interpretaciones de la realidad contemporánea ${ }^{75}$. Con todo, no cabe duda de que el DF jugó un rol reseñable en este proceso de reactualización, tanto por su interés en emprender una renovación de las fuentes teóricas, como por su capacidad para ser oído en las aulas.

Por último, resta referirse al programa docente en este período. Como se ha comentado, los cursos 1964-1965 y 1965-1966 fueron de búsqueda y renovación de la enseñanza. En estos años se desarrollaron programas experimentales que debían ser siempre discutidos en los seminarios docentes celebrados cada semana y divididos en tres grupos de acuerdo con el área en el que se impartía clase. Se

\footnotetext{
${ }^{72}$ Una visión crítica puede verse en la revista Pensamiento Crítico, La Habana, enero 1970, n. 36, pp. 210-218: MARTÍNEZ HEREDIA, Fernando. Althusser y el marxismo.

${ }_{73}^{73}$ Lautaro publicó El materialismo histórico y la filosofía de Benedetto Croce, 1958; Los intelectuales y la organización de la cultura, 1960; Literatura y vida nacional, 1961; y Notas sobre Maquiavelo, sobre la política y sobre el Estado moderno, 1962. Sobre la recepción de Gramsci en Cuba véase ACANDA GONZÁLEZ, Jorge L. La recepción de Gramsci en Cuba. En: KANOUSSI, Dora (ed.). Gramsci en América. II Conferencia Internacional de Estudios Gramscianos. México D. F.: Plaza y Valdés, 2000, pp. 109-128.

Véase MARTÍNEZ HEREDIA, Fernando. Gramsci en la Cuba de los años sesenta. En: SÁNCHEZ QUIRÓZ, Magdiel. Fernando Martínez Heredia... Op. cit., pp. 177-190.

${ }^{75}$ Acaso el ejemplo más claro sea el de Casa de las Américas, clave en la difusión del pensamiento de José Carlos Mariátegui, Frantz Fanon, Louis Althusser o Régis Debray, entre otros.
} 
practicó como política del DF que los grupos por facultades tuvieran programas diferenciados, pero estos habían de ser previamente defendidos por escrito y ante el colectivo. Sobre esta etapa, Aurelio Alonso recuerda que llegó un momento en que cada profesor tenía su programa propio. En su caso, introdujo aspectos vinculados a la dialéctica de la naturaleza, dada su afinidad con esta rama del pensamiento marxista y su trabajo en el área de ciencias ${ }^{76}$. Este recurso a la indagación buscaba acelerar el encuentro de soluciones a la enseñanza de la filosofía marxista.

Gracias a las discusiones semanales y a las lecturas realizadas, se fue introduciendo con fuerza la necesidad de aproximarse al marxismo desde una perspectiva histórica y crítica, visión en la que habría tenido particular protagonismo Fernando Martínez Heredia ${ }^{77}$. Esta suponía analizar a los pensadores y sus aportes poniéndolos en relación con las circunstancias sociohistóricas en las que habían vivido y se habían escrito y desarrollado. Para el DF, sólo a través de esta perspectiva se podía lograr una interpretación cabal de la evolución de la teoría marxista a lo largo de su historia y evitar que se explicasen sus categorías y leyes generales descontextualizadas de su escenario de creación, como fórmulas inmutables en el tiempo.

La aproximación histórica al marxismo se reflejaba ya en un programa docente explicado hacia 1965 por Fernando Martínez Heredia ${ }^{78}$. En este se observa un cambio en el abordaje de la materia. Se incluía un apartado introductorio en el que Martínez Heredia explicaba al alumnado cuáles eran las tres dificultades por encarar en la docencia de la filosofía marxista. La primera guardaba relación con la insuficiencia de los lenguajes marxistas, los dogmas y el predominio del manualismo. La segunda se relacionaba con la necesidad de modificar el método de exposición: apostar por la perspectiva histórica y crítica, en detrimento del método lógico y la descripción y teorización de situaciones. En la tercera, referente a los textos base, se hacía hincapié en el uso de los clásicos y en la explicación de la historia del pensamiento marxista como paso ineludible para su comprensión. En dicho programa se apostaba por interpretar la génesis y la evolución de la teoría marxista a partir de las circunstancias sociohistóricas en las que ambos procesos se habían desarrollado.

Tras esta sugerente introducción, el programa de Martínez Heredia comenzaba con "El origen de la sociedad de clases" (fases evolutivas según Engels, tránsito a la sociedad de clases, la formación del Estado y el origen de la conciencia social). Y a continuación, aparecía un segundo apartado dedicado íntegramente a la explicación de los factores sociales, económicos y políticos que rodearon al origen del marxismo y un análisis de la trayectoria del pensamiento de Marx hasta alcanzar la posición gnoseológica que posibilitó, en un momento dado, la elaboración de una teoría científica de la sociedad. Los siguientes apartados se dedicaban a la explicación del materialismo histórico y materialismo dialéctico, bajo un esquema más convencional.

\footnotetext{
${ }^{76}$ Entrevista con Aurelio Alonso, 13-11-2017; y testimonio de A. Alonso recogido en KOHAN, Néstor. Pensamiento Crítico y el debate por las ciencias sociales... Op. cit., p. 407.

${ }^{77}$ Entrevista con Aurelio Alonso, 06-12-2018.

78 DPNP: "Programa correspondiente a la parte del curso de Filosofía Marxista que explicara el profesor Fernando Martínez Heredia", s.f. (ca. 1965), 5 pp.
} 
Desechar un manual como recurso básico para la enseñanza no siempre conduce a una ruptura con su esquema de pensamiento, o no de inmediato. EI DF en estos años ejemplificaba el trecho que mediaba entre una ruptura parcial, en tanto que rechazo a los vehículos pedagógicos utilizados hasta ahora, y una ruptura total, en un sentido de quiebre con el esquema de pensamiento que estos reflejaban. Si bien es cierto que se dieron pasos hacia la transformación y cubanización de la materia y se comenzó a introducir la aproximación histórica al marxismo, no se produjo aún una crítica totalizadora del esquema del pensamiento detrás de los manuales ni de la tradicional sistematización plasmada en ellos. Prueba de esto es que, cuando se creen grupos de investigación en el colectivo, hacia 1965, estos se dedicaban a la Dialéctica de la Naturaleza, Dialéctica de la Sociedad y Dialéctica del Pensamiento. Aunque la preeminencia de la dialéctica marcaba distancia con el positivismo, estos grupos se ocupaban de los tres ámbitos que canónicamente cubría el marxismo en tanto que ciencia de las leyes más generales de la naturaleza, sociedad y pensamiento.

A un período de búsqueda le sigue, eventualmente, uno de maduración. Para el DF este avance sobrevendría a partir de 1965, cuando los debates, replanteamientos y lecturas de los años previos abrieron paso a las investigaciones, un programa unificado y fundamentado en la perspectiva histórica y la publicación de materiales de enseñanza y medios de difusión propios. En la segunda mitad de los sesenta, el DF dará pasos en su rechazo al manualismo y pondrá por escrito críticas a sus contenidos y a lo que estos representaban en la dogmatización de la teoría marxista $^{79}$.

\section{Conclusiones}

La evolución del Departamento de Filosofía durante sus dos primeras etapas es clave para interpretar la dimensión político-ideológica de la Revolución. La historia de este centro refleja las prioridades y las deficiencias a las que se ha de enfrentar cualquier proceso de transformación radical que busque quebrar un estatus dependiente. En particular, ilustra la diferenciación, para el caso cubano, entre una primera mitad de los sesenta caracterizada por la espontaneidad, la provisionalidad y las contradicciones a la hora de dar respuesta a los numerosos retos planteados a la dirección política; y una segunda mitad de la década con medios y objetivos más delimitados, con especial énfasis en la definición de una identidad propia de la Revolución, la construcción de un socialismo independiente y la visión del comunismo como cambio social integral.

El proceso de creación y formación acelerada del DF, así como el uso de manuales soviéticos, refleja la búsqueda de respuestas urgentes ante las prioridades de la Revolución. La carencia de cuadros y textos nacionales se suplió con recursos y materiales extranjeros. El primer ejemplo al que se miró fue el del bloque del este,

\footnotetext{
${ }^{79}$ En 1966 se produjo la llamada "Polémica de los Manuales". Este debate, desarrollado en la revista Teoría y Práctica, giró en torno a la conveniencia de usar los manuales extranjeros para la enseñanza de la filosofía marxista y enfrentó a A. Alonso del DF (en contra de su uso y con críticas hacia sus contenidos) y a profesorado de las EIR, a favor del uso de los manuales en determinados niveles. Esta polémica reflejó las distintas posturas mantenidas por el DF y las EIR sobre la metodología de la enseñanza. Véase PEDEMONTE, Rafael. Una relación tensa y ambivalente... Op. cit., pp. 163-170.
} 
el más accesible en aquellos momentos.

La segunda etapa fue de experimentación y búsqueda, alimentada por los debates suscitados en la Revolución y las orientaciones de Dorticós hacia una cubanización de la enseñanza del marxismo y el alejamiento del esquematismo. En 1962 había emergido la crítica política al comunismo del este y la ortodoxia nacional. Tras ella, los cuestionamientos se extendieron al campo económico y cultural primero y de forma pública, y al ámbito de la enseñanza del marxismo, más tarde.

La tendencia desde entonces será rechazar los textos soviéticos y buscar nuevas referencias, mas sin lograr una ruptura total con la sistematización filosófica que aquellos transmitían. Para criticar un sistema político, económico o ideológico ha de conocerse a cabalidad. El Capital es buena prueba de ello. Los miembros del DF habían sido educados a través de los manuales y continuaron en proceso de formación en los años posteriores a la fundación del centro. Se necesitaba un manejo de la teoría marxista, lecturas y nuevos referentes para dar el salto del rechazo al manualismo a una crítica de su sistematización filosófica.

Este proceso de deconstrucción vendrá progresivamente desde 1965. En el segundo lustro de los sesenta apostaron por la enseñanza histórico-crítica del marxismo frente a la lógica plasmada en los manuales. Esto suponía aprehender a los pensadores de cada época y sus formulaciones en estrecha relación con las circunstancias sociohistóricas en las que se habían creado y desarrollado. Se interpretaba la historia del marxismo y su evolución como un proceso dinámico y polémico, por lo que se debían analizar también las fuentes de inspiración del marxismo (la filosofía clásica alemana, por ejemplo), aquellas corrientes que polemizaron con este y las diferentes aproximaciones que aparecieron en la historia del comunismo tradicional durante el siglo XX. En esta línea, el DF reivindicará la autoctonía de la Revolución y la necesidad de teorizar una vertiente marxista propiamente cubana, síntesis del pensamiento filosófico nacional, de los próceres independentistas del XIX, de los pensadores de las décadas del 1920 y 1930 y, en particular, la generación histórica de la Revolución del 1959. Y todos estos elementos, a partir de la ubicación de Cuba como país con un pasado colonial y dependiente que marcaba particularidades frente al bloque socialista y lo aproximaba al tercer mundo.

Desde 1965, el DF creó su programa docente propio, en el que ganará presencia el historicismo (la asignatura se llamará luego Historia del Pensamiento Marxista), los procesos revolucionarios del tercer mundo, la tradición cubana y pensadores heterodoxos no recogidos en los manuales. Publicarían sus materiales propios para la enseñanza, en los que se reflejaba esa toma de posición. En ellos sólo habrá cabida para los clásicos del marxismo, la nueva izquierda intelectual europea y estadounidense, los dirigentes cubanos y los movimientos de liberación antiimperialista, a los que se les añadieron investigaciones del colectivo, incrementadas paulatinamente hasta su dispersión en 1971.

Por último, la apuesta del DF por un marxismo crítico con los productos soviéticos y afín al paradigma revolucionario cubano hará que su proyecto confluya con el de la dirigencia de la Revolución. En la segunda mitad de los sesenta, el 
colectivo conquistó espacios nacionales, ganó presencia en eventos internacionales como la Conferencia de la Organización de Solidaridad de los Pueblos de África, Asia y América Latina -la "Tricontinental", en 1966- y entró a formar parte de los circuitos progresistas intelectuales. Sus productos, Caimán Barbudo y, particularmente, Pensamiento Crítico son símbolos de este crecimiento, revistas en las que se promocionó una retórica de cambio favorable a una revolución global contra el imperialismo (emblema de Cuba entre 1966 y 1968) y se difundieron textos clave para la construcción identitaria de la oleada de nueva izquierda.

Estos avances y respuestas cosechados en la segunda mitad de los sesenta se produjeron gracias a las lecturas, los cuestionamientos y el contexto previos. Lo uno sin lo otro no hubiese sido posible. Cada etapa estuvo marcada por sus tiempos, deficiencias y necesidades, como lo estuvo la misma Revolución. Para "Incendiar el Atlántico" había que prender antes una mecha de renovación.

\section{Bibliografía}

ACANDA GONZÁLEZ, Jorge L. La recepción de Gramsci en Cuba. En: KANOUSSI, Dora (ed.). Gramsci en América. II Conferencia Internacional de Estudios Gramscianos. México D. F.: Plaza y Valdés, 2000, pp. 109-128.

ALBURQUERQUE, Germán. Cuba en el Movimiento de Países No Alineados: el camino al liderazgo. Causas y motivaciones. 1961-1983. Caravelle. Cahiers du monde hispanique et luso-brésilien [en línea]. 2017, n. 109, pp. 179-193. [Consulta: 17-08-2021]. Disponible en <https://doi.org/10.4000/caravelle.2518>.

ALONSO, Aurelio. Marxismo y espacio de debate en la Revolución Cubana. Temas. 1995, vol. 1, n. 3, pp. 34-43.

ARTARAZ, Kepa. Cuba y la nueva izquierda: una relación que marcó los años 60. Buenos Aires: Capital Intelectual, 2011. 301 p.

ARTARAZ, Kepa. El ejercicio de pensar: the rise and fall of Pensamiento Crítico. Bulletin of Latin American Research [en línea]. 2005, vol. 24, n. 3, pp. 348-366. [Consulta: 17-08-2021]. Disponible en <https://onlinelibrary.wiley.com/doi/pdf/10.1111/j.0261-3050.2005.00139.x>.

BELL LARA, José; LÓPEZ GARCÍA, Delia L. y CARAM LEÓN, Tania (comps.). Documentos de la Revolución Cubana, 1962. La Habana: Editorial de Ciencias Sociales, 2009. 547 p.

BELL LARA, José; LÓPEZ GARCÍA, Delia L. y CARAM LEÓN, Tania (comps.). Documentos de la Revolución Cubana, 1965. La Habana: Editorial de Ciencias Sociales, 2013. 446 p.

Biblioteca Nacional José Martí. Multimedia Pensamiento Crítico. Una revista para el ejercicio de pensar [CD-ROM]. La Habana: Biblioteca Nacional José Martí, 2016. S. pág. 
BUNCK, Julie Marie. Fidel Castro and the quest for a revolutionary culture in Cuba. Pennsylvania: Pennsylvania State University Press, 1994. 237 p.

CASTRO, Fidel. Discurso pronunciado en el acto homenaje a los mártires del Asalto al Palacio Presidencial [en línea]. Universidad de La Habana, 13-03-1962. [Consulta: 17-08-2021]. Disponible <http://www.cuba.cu/gobierno/discursos/1962/esp/f130362e.html>.

CASTRO, Fidel. Discurso pronunciado en las conclusiones del Primer Congreso Nacional de Maestros de Vanguardia "Frank País", conjuntamente con el acto de graduación de las EBIR [en línea]. La Habana, 10-04-1963. [Consulta: 17-082021]. Disponible <http://www.cuba.cu/Gobierno/discursos/1963/esp/f100463e.html>.

CHOMSKY, Aviva. A history of the Cuban Revolution. Malden: Wiley Blackwell, 2015. $232 \mathrm{p}$.

DÍAZ SOSA, Fidel. El proceso de difusión del marxismo soviético en Cuba. Apuntes preliminares. En: PLÁ LEÓN, Rafael y GONZÁLEZ ARÓSTEGUI, Mely del R. (coords.). Marxismo y Revolución: escena del debate cubano en los sesenta. La Habana: Editorial de Ciencias Sociales; Centro de Investigación y Desarrollo de la Cultura Cubana Juan Marinello, 2006, pp. 78-96.

DÍAZ, Jesús. El fin de otra ilusión. A propósito de la quiebra de El Caimán Barbudo y la clausura de Pensamiento Crítico. Encuentro de la cultura cubana. 2000, n. 1617, pp. 106-119.

DORTICÓS, Osvaldo y HART, Armando. Mensaje educacional al pueblo de Cuba. La Habana: Ministerio de Educación de Cuba, 1960. 122 p.

FAGEN, Richard. The Transformation of Political Culture in Cuba. Standford: Standford University Press, 1969. $271 \mathrm{p}$.

FURSENKO, Aleksandr y NAFTALI, Timothy. "One Hell of Gamble": Kruschev, Castro, and Kennedy, 1958-1964. New York: W. W. Norton \& Co, 1998. 420 p.

GÓMEZ VELÁZQUEZ, Natasha. La divulgación del marxismo en la revista Pensamiento Crítico. En: PLÁ LEÓN, Rafael y GONZÁLEZ ARÓSTEGUI, Mely del R. (coords.). Marxismo y Revolución: escena del debate cubano en los sesenta. La Habana: Editorial de Ciencias Sociales; Centro de Investigación y Desarrollo de la Cultura Cubana Juan Marinello, 2006, pp. 97-121.

GONZÁLEZ ARÓSTEGUI, Mely del R. Las Plenarias Nacionales Universitarias de profesores de Filosofía: reflexiones y polémicas en su entorno. En: PLÁ LEÓN, Rafael y GONZÁLEZ ARÓSTEGUI, Mely del R. (coords.). Marxismo y Revolución: escena del debate cubano en los sesenta. La Habana: Editorial de Ciencias Sociales; Centro de Investigación y Desarrollo de la Cultura Cubana Juan Marinello, 2006, pp. 65-77. 
GONZÁLEZ LAGE, Valeria. Más allá de la isla. El rol cubano en la configuración de un imaginario revolucionario para América Latina, 1960s. En: ALCÁNTARA, Manuel; GARCÍA, Mercedes y SÁNCHEZ, Francisco (coords.). Memoria del 56º Congreso Internacional Americanistas. Salamanca: Universidad de Salamanca, 2018, pp. 433-443.

GORDY, Katherine A. Living ideology in Cuba: Socialism in principle and practice. Ann Arbor. Michigan: University of Michigan Press, 2015. 284 p.

GUANCHE, Julio C. El continente de lo posible. Un examen sobre la condición revolucionaria [en línea]. La Habana: Ruth Casa Editorial; Instituto Cubano de Investigación Cultural Juan Marinello, 2008. 215 p. [Consulta: 17-08-2021]. Disponible en <https://jcguanche.files.wordpress.com/2021/03/el-continente-delo-posible.-julio-cesar-guanche.pdf $>$.

GUERRA, Sergio y MALDONADO, Alejo. Historia de la Revolución Cubana. Navarra: Txalaparta, 2009. 297 p.

GUEVARA, Ernesto. Apuntes críticos a la economía política. La Habana: Ocean Sur, 2006. $431 \mathrm{p}$.

GUEVARA, Ernesto. Apuntes filosóficos. La Habana: Ocean Sur, 2012. 435 p.

KAPCIA, Antoni. A short history of revolutionary Cuba: Revolution, Power, Authority and the State since 1959. London: Bloomsbury Publishing, 2021. 229 p.

KAPCIA, Antoni. Cuba in revolution. A history since the fifties. London: Reaktion Books, 2008. 208 p.

KAROL, Kewes S. Los guerrilleros en el poder. Itinerario político de la revolución cubana. Barcelona: Seix Barral, 1972. 658 p.

KOHAN, Néstor. Marx en su (Tercer) Mundo. Hacia un socialismo no colonizado. La Habana: Centro de Investigación y Desarrollo de la Cultura Cubana Juan Marinello, 2003. 302 p.

KOHAN, Néstor. Pensamiento Crítico y el debate por las ciencias sociales en el seno de la Revolución cubana. En: LEVY, Bettina (ed.). Crítica y teoría en el pensamiento social latinoamericano [en línea]. Buenos Aires: CLACSO, 2006, pp. 389-437. [Consulta: 17-08-2021]. Disponible en <http://bibliotecavirtual.clacso.org.ar/ar/libros/becas/critica/C07NKohan.pdf>.

KRUIJT, Dirk; REY TRISTÁN, Eduardo y MARTÍN ÁLVAREZ, Alberto (eds.). Latin American Guerrilla Movements. Origins, Evolution, Outcomes. New York: Routledge, 2020. 237 p.

LEÓN DEL RíO, Yohanka. Avatares del marxismo en la década del sesenta en Cuba. En: PLÁ LEÓN, Rafael y GONZÁLEZ ARÓSTEGUI, Mely del R. (coord.). Marxismo y Revolución: escena del debate cubano en los sesenta. La Habana: 
Editorial de Ciencias Sociales; Centro de Investigación y Desarrollo de la Cultura Cubana Juan Marinello, 2006, pp. 58-64.

MARTÍN ÁLVAREZ, Alberto y REY TRISTÁN, Eduardo. La oleada revolucionaria latinoamericana contemporánea, 1959-1996. Definición, caracterización y algunas claves para su análisis. Naveg@mérica. Revista electrónica de la Asociación Española de Americanistas [en línea]. 2012, n. 9. [Consulta: 17-082021].

Disponible en: $<$ https://digitum.um.es/digitum/bitstream/10201/36767/1/161591-596161-1PB.pdf $>$.

MARTÍN SABINA, Elvira (ed.). La Reforma Universitaria de 1962: Medio siglo de impacto en la Educación Cubana. La Habana: Félix Varela, 2012. 163 p.

MARTÍNEZ HEREDIA, Fernando. A viva voz. La Habana: Editorial de Ciencias Sociales, 2010. 308 p.

MARTÍNEZ HEREDIA, Fernando. El ejercicio de pensar. La Habana: Editorial de Ciencias Sociales, 2010. $158 \mathrm{p}$.

MARTÍNEZ PÉREZ, Liliana. Los hijos de Saturno: intelectuales y revolución en Cuba. México D. F.: Miguel Ángel Porrúa-FLACSO, 2006. 412 p.

MEDIN, Tzvi. Cuba: The Shaping of Revolutionary Consciousness. London: Lynne Rienner Publishers, Inc., 1990. 191 p.

MISKULIN, Silvia Cezar. Os intelectuais cubanos e a política cultural da Revolução (1961-1975). São Paulo: Alameda Casa Editorial, 2009. 301 p.

ORTEGA REYNA, Jaime. Incendiar el océano. Notas sobre la(s) recepción(es) de Althusser en Cuba. De Raíz Diversa. Revista especializada en estudios latinoamericanos [en línea]. 2015, vol. 2, n. 4, pp. 129-153. [Consulta: 17-082021]. $\quad$ Disponible $<$ https://biblat.unam.mx/hevila/Deraizdiversa/2015/vol2/no4/5.pdf>.

PEDEMONTE, Rafael. Una relación tensa y ambivalente: el medio intelectual cubano ante "lo soviético" en los primeros años revolucionarios (1959-1966). Historia [en línea]. 2017, vol. 1, n. 50, pp. 141-173. [Consulta: 17-08-2021]. Disponible en $<$ http://dx.doi.org/10.4067/S0717-71942017000100006>.

PÉREZ-STABLE, Marifeli. La Revolución cubana: orígenes, desarrollo y legado. Madrid: Editorial Colibrí, 1998. 371 p.

ROJAS, Rafael. Traductores de la utopía. La Revolución cubana y la nueva izquierda de Nueva York. México: FCE, 2016. 279 p.

SÁNCHEZ QUIRÓZ, Magdiel (comp.). Fernando Martínez Heredia. Pensar en tiempo de Revolución. Antología esencial [en línea]. Buenos Aires: CLACSO, 2018. 1341 p. [Consulta: 17-08-2021]. Disponible en 
$<$ http://biblioteca.clacso.edu.ar/clacso/se/20180524041744/Antologia Fernando Martinez Heredia.pdf>.

SUÁREZ SALAZAR, Luis y KRUIJT, Dirk. La Revolución Cubana en Nuestra América: el internacionalismo anónimo. Panamá: Ruth Casa Editorial, 2015. 780 p.

YAFFE, Helen. Che Guevara: the economics of revolution. London: Palgrave Macmillan, 2009. 354 p. 